\title{
Analytical modeling of reinforced concrete columns subjected to bidirectional shear
}

\author{
By: Edison Osorio ${ }^{1}$, Jesús M. Bairán ${ }^{2}$, Antonio R. Marí ${ }^{2}$ \\ ${ }^{1}$ Facultad de Ingeniería Civil, Universidad Antonio Nariño, Bogotá, Colombia \\ ${ }^{2}$ Departament of Civil and Environmental Engineering, Universitat Politècnica de Catalunya (UPC), \\ Campus Nord, C1 buildings, Jordi Girona, 1, 08034 Barcelona, Spain
}

Corresponding author: Edison Osorio, e.osorio@uan.edu.co

Tel: +34 (93) 40165 08; Fax: +34 (93) 4011036

\begin{abstract}
Under general seismic loading, reinforced concrete columns may be subjected to lateral loads in more than one direction. Available experimental data on columns subjected to bidirectional forces indicate that higher levels of damage and a higher loss of ductility and strength have been observed compared to similar tests under unidirectional shear forces. In this study, an experimental program was conducted in which six lightly reinforced concrete columns were subjected to unidirectional and bidirectional cyclic shear forces. This observation was used to identify the mechanisms and parameters governing the behavior of columns subjected to cyclic bidirectional lateral loads. Hence, a new conceptual model was developed to obtain the capacity of member. The shear forces were analyzed and an analytical formulation was derived to account for the effects in the concrete stress-strain relationship, the moment-curvature diagram and the plastic hinge length. These equations were used along with a structural model with concentrated plastic hinges to obtain the capacity curve of the column. The results of the formulations developed were verified using the results of the experiments performed on columns subjected to unidirectional and bidirectional cyclic lateral forces.
\end{abstract}

Keywords: reinforced concrete, bidirectional cyclic loading, stress-strain, moment-curvature, plastic hinge length, displacement capacity, strength degradation

\section{Introduction}

Under seismic action, reinforced concrete columns can be subjected to lateral displacements in several directions. The magnitude of the displacement in each direction depends on the dynamic response of the structure, the orientation of the structure in the earthquake direction, the distance to the epicenter and the magnitude and direction of the aftershocks, among other factors. Such movements produce cyclic flexural and normal forces in combination with bidirectional shear forces.

In the limited available experimental data on columns subjected to bidirectional forces, higher levels of damage and a higher loss of ductility and strength have been observed compared to similar tests under unidirectional shear forces. These experimental data are compiled in [1] and subsequently tests were conducted by [2-5]. In the scientific literature, only a decrease in the contribution of concrete to the shear strength was mentioned in [6] and was later refined in $[7,8]$. It is essential to elucidate this mechanism to make recommendations and develop methodologies for the assessment of columns under bidirectional seismic forces.

To gain insight into the mechanism of the aforementioned problem, an experimental program was carried out on circular columns with light transverse reinforcement, common in older existing reinforced concrete buildings. Those were affected by shear forces under the action of unidirectional and bidirectional lateral loads [9]. The primary results of the study were that the strains in the stirrups produced by the shear forces and the confinement action could be accumulated by alternating the direction of the lateral loads.

The primary objective of this study was to identify the mechanisms and parameters governing the behavior of columns subjected to bidirectional lateral loads. For this purpose, the effects of the shear forces were analyzed 
at the material, section and member levels, and analytical expressions were derived to account for these effects in the concrete stress-strain relationship, the moment-curvature diagram and the plastic hinge length. These equations were used along with a structural model with concentrated plastic hinges to obtain the capacity curve of the column. The results of the formulations developed were verified using results from the experiments performed on columns subjected to unidirectional and bidirectional cyclic lateral forces. Good agreement was obtained between the experimental observations and the formulation developed.

\section{Effects of shear forces at material level}

In a reinforced concrete column, both the longitudinal and transverse reinforcements provide resistance to the flexural, axial and shear forces simultaneously. The transverse reinforcement resists the shear force and confines the concrete core, thereby increasing its strength and ductility. Similarly, the longitudinal reinforcement and the concrete participate in the shear resisting mechanism. All of these mechanisms interact with each other such that the degradation of one mechanism affects the other mechanisms [10].

\subsection{Effects of shear forces on confinement stresses}

Currently, in the seismic design or assessment of a reinforced concrete column, the compressive strength of the confined concrete in a column is determined by assuming that the column is subjected only to a compression force (see Figure 1a) using Mander's model [11]. In this study, we suggest that the confinement stress is reduced by the presence of a concurrent shear force, as shown in Figure 1b. Consequently, the effective confinement stresses in two directions $\left(\sigma_{e, x}, \sigma_{e, y}\right)$ can be calculated using equations (1) and (2):

$$
\begin{gathered}
\sigma_{e, x}=\alpha \frac{2 \cdot A_{s t} \cdot\left(f_{y t}-\sigma_{s v}\right)}{s \cdot D_{c}} \\
\sigma_{e, y}=\alpha \frac{2 \cdot A_{s t} \cdot f_{y t}}{s \cdot D_{c}}
\end{gathered}
$$

where $A_{s t}$ is the area of the stirrups or the spiral; $f_{y t}$ is the yielding strength of the stirrups; $\sigma_{s v}$ is the stress in the transverse reinforcement from the shear force; $s$ is the stirrups spacing; $D_{c}$ is the center-to-center diameter of the stirrups; and $\alpha$ is a factor that represents the confinement efficiency, which can be obtained using Mander's model [11].

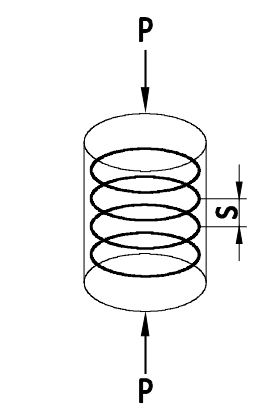

Ast:fyt

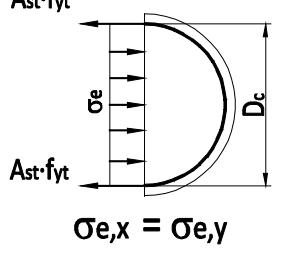

(a) Lateral confinement stresses under axial load only

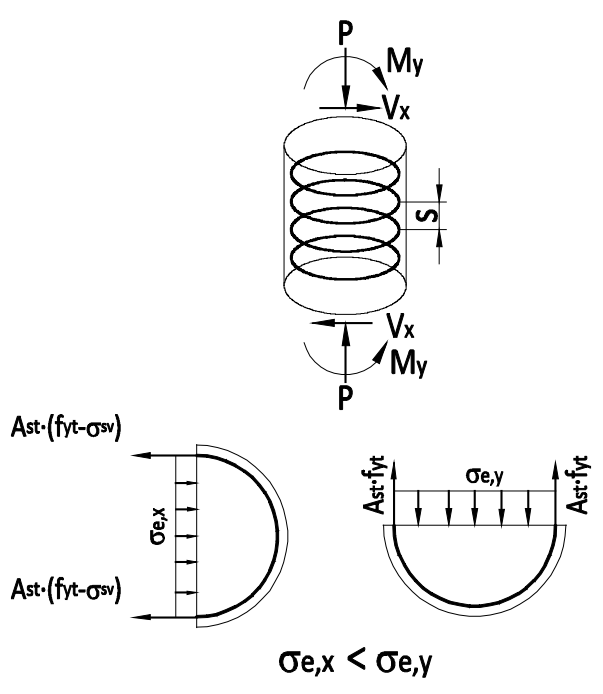

(b) Lateral confinement stresses under combined axial load, bending moment and shear force

\section{Figure 1 Conceptual model used to determine confinement stresses}

Here, the confinement stresses $\left(\sigma_{e, x}, \sigma_{e, y}\right)$ are used to obtain the characteristics of the stress-strain curve of the confined concrete. Recall that the asymmetric confinement stresses provide the confined concrete with less confinement capacity than that provided by symmetric confinement stresses, as shown in Figure 2. 


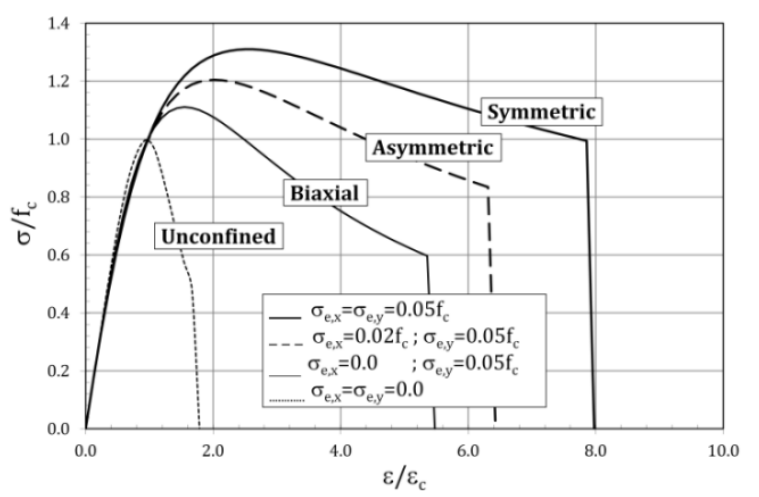

Figure 2 Effects of confinement stress on strain-stress relationship of confined concrete

\subsection{Effect of bidirectional shear forces on concrete ductility}

In the seismic prediction response of a reinforced concrete column, the ultimate strain in confined concrete has been obtained taking into account that the column is under axial load with empirical [12-15] or energy balance approaches $[11,16]$. In this study, experimental observations showed that under cyclic shear forces applied in two directions (X and $\mathrm{Y}$ ), the strains induced by the shear forces $\left(\varepsilon_{s v}^{j}\right)$ at the transverse reinforcement accumulate with the strains produced by the dilatancy of concrete in compression $\left(\varepsilon_{s c}^{i}\right)$, as shown in Figure 3. Consequently, the total strain at the stirrup $\left(\varepsilon_{s t}^{i}\right)$ is given by equation (3). The superscripts ( $i$ or $j$ ) denote the direction $x$ or $y$ evaluated, respectively.

$$
\dot{\varepsilon}_{s t}^{i}=\varepsilon_{s v}^{j}+\dot{\varepsilon}_{S C}^{i}
$$

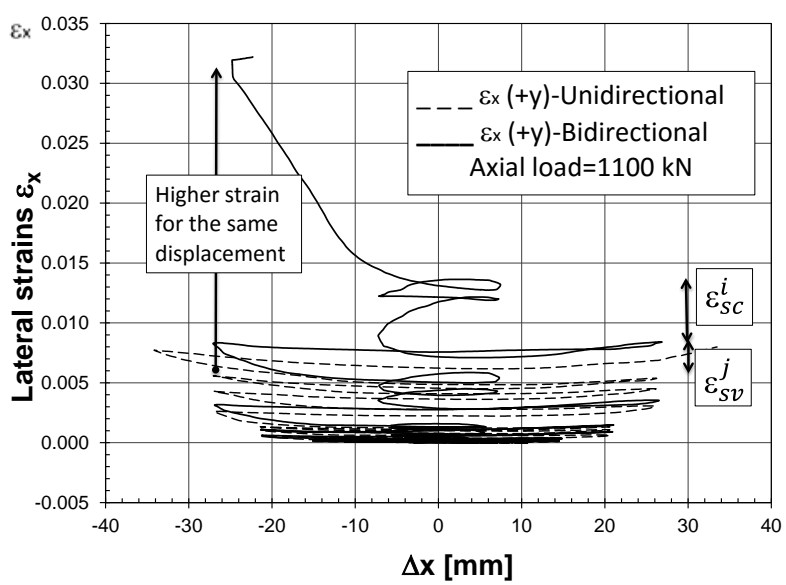

Figure 3 Experimental measures of evolution of lateral strains under bidirectional and unidirectional tests [9]

There are two ways of quantitatively interpreting the equation given above.

a) The effective deformation capacity for confinement $\left(\varepsilon_{\mathrm{sc}}^{\mathrm{i}}\right)$ is considered to be the ultimate strain in the stirrup $\left(\varepsilon_{s u}^{i}\right)$ minus the strain produced by the shear forces $\left(\varepsilon_{\mathrm{sv}}^{\mathrm{j}}\right)$, as shown in equation (4):

$$
\varepsilon_{s c}^{i}=\varepsilon_{s u}^{i}-\varepsilon_{s v}^{j}
$$

Therefore, a portion of the strain-energy of the transverse steel is required to resist the shear decreasing the energy to confine the concrete and consequently its ultimate deformation. The effective stirrup strain $\left(\varepsilon_{s c}^{i}\right)$ and the effective lateral confinement stresses must be used to calculate the effective deformation capacity of the concrete core $\left(\varepsilon_{c u, e}^{i}\right)$ in Paulay's approach [16], as given by equation (5). However, the quantitative effect of the bidirectional shear forces on the ultimate strain in the unconfined concrete cannot be obtained using equation (5).

$$
\varepsilon_{c u, e}^{i}=\varepsilon_{c p}+\frac{1.4 \alpha \cdot \rho_{s}\left(\boldsymbol{f}_{\boldsymbol{y t}}-\frac{\sigma_{s v}^{i}}{\mathbf{2}}\right)\left(\varepsilon_{s u}^{i}-\varepsilon_{s v}^{j}\right)}{f_{c c}}
$$


where $\varepsilon_{c p}$ is the ultimate strain in the unconfined concrete, $f_{c c}$ is the peak strength of the confined concrete, $\rho_{s}$ is the volumetric ratio of the transverse reinforcement and $\varepsilon_{s u}^{i}$ is the ultimate strain in the transverse steel reinforcement.

b) Alternatively, in this second approach, we take into account that the lateral strains produced by the shear force reduce the concrete strength, as has been widely studied in the literature (see for example $[17,18]$ ). One can consider the decrease in the concrete strength from the lateral tensile strains produced by the shear forces (Figure 4a). When the column is also loaded in the orthogonal direction, the concrete in the lateral strain is loaded in compression (Figure 4b).

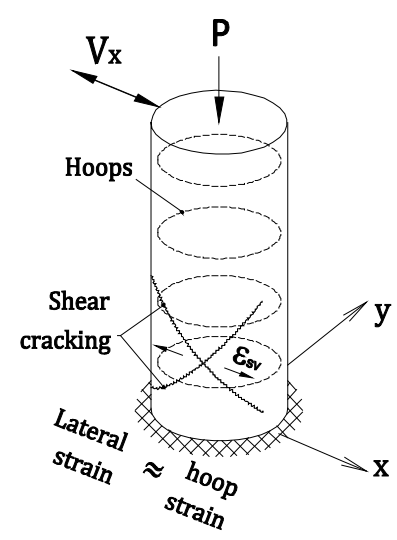

(a) Lateral strain in concrete induced by shear forces

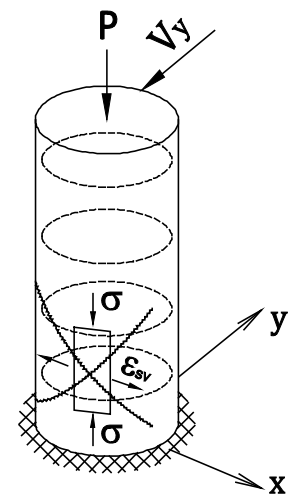

(b) Concrete zone with residual lateral strain under compression

Figure 4 Effects of bidirectional shear forces on concrete

The following approach was developed based on the stress-lateral and longitudinal strain of concrete response to estimate the ultimate strain in both confined and unconfined concrete with residual lateral deformations. An idealization of the behavior of the lateral-longitudinal strain in concrete under compression with and without lateral confinement stresses was established, as shown in Figure 5a. A nonlinear dilatancy relationship can be used to determine the decrease in the deformation capacity of the concrete from the residual lateral strains $\left(\varepsilon_{c u, e}^{i}\right)$ using the ultimate dilation ratio $\left(\psi_{u}\right)$, see equation (6). The effects of the pre-lateral strain on the stresslongitudinal strain response for concrete in compression are shown in Figure 5b.

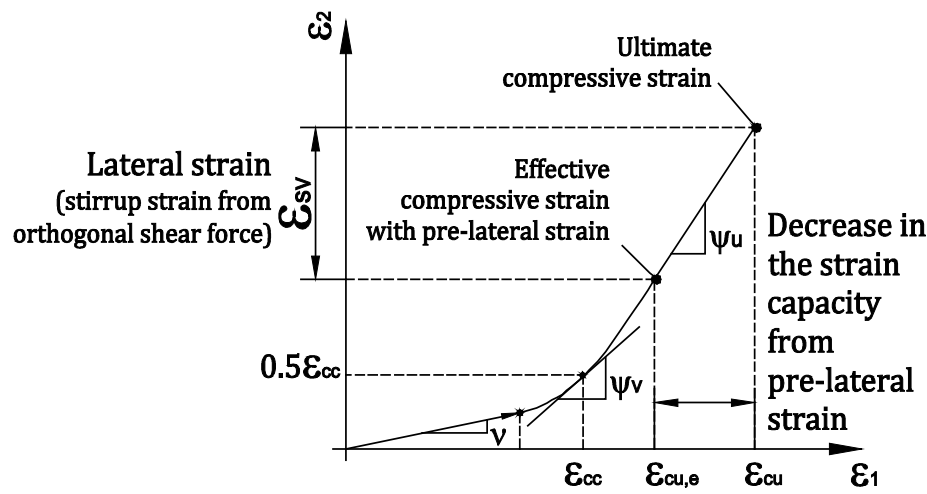

(a) Lateral-longitudinal strain diagram of concrete in compression

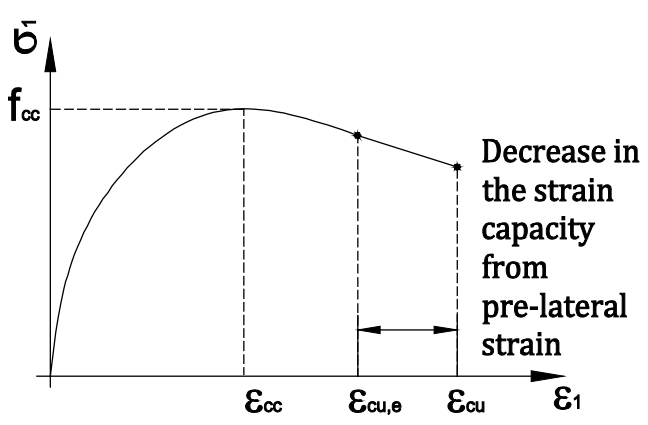

(b) Stress-longitudinal strain diagram of concrete in compression

Figure 5 Decrease in the strain capacity of compressed concrete from pre-lateral strain

$$
\varepsilon_{c u, e}^{i}=\varepsilon_{c u}^{i}-\frac{\varepsilon_{s v}^{j}}{\psi_{u}} \geq\left\{\begin{array}{l}
\varepsilon_{c c} \\
\frac{f_{y}}{E_{s}}
\end{array}\right.
$$


where $f_{y}$ and $E_{s}$ are the yielding strength and the elastic modulus of the longitudinal reinforcing steel, respectively. The $\varepsilon_{c c}$ limit represents the dilatancy use applicability and $\frac{f_{y}}{E_{s}}$ limit is proposed to take into account the contribution to the strain capacity of the column longitudinal reinforcement.

The dilation ratio depends on the concrete type and the magnitude of the confinement stresses. Experimental measurements on concrete strength classes between C35 and C60 under uniaxial compression have been used to develop the following expression for the dilation angle at the post-peak branch in terms of the unconfined and confined strength of the concrete [9,19]:

$$
\psi_{u}=1+\left(0.25 \mathrm{e}^{2.8\left(\frac{f_{c}}{50}\right)}-1\right) \exp \left[-5\left(\frac{f_{c c}}{f_{c}}-1\right)\right]
$$

\subsection{Estimate of stirrups strain under shear forces}

The strain in the transverse reinforcement $\left(\varepsilon_{\text {sv }}^{j}\right)$ produced by shear forces can be estimated by refined approaches [20-23]. We have suggested a simplified approach based on a strut-and-tie mechanism [10] and taking into account the following considerations.

The shear strength $\left(V_{u}\right)$ of the columns under seismic forces can be obtained by summing the transverse reinforcement contribution $\left(V_{s}\right)$ and the arch effect contribution $\left(V_{p}\right)$, see equation (8). In this approach, other concrete contributions to the shear resistance (namely, aggregate interlock, dowel action, etc.) are neglected because experimental measurements show that these contributions decrease as the number of cycles and ductility demand increase $[11,18,19]$.

$$
V_{u}=V_{s}+V_{p}
$$

The transverse reinforcement starts to contribute when the first shear crack occurs in the concrete. The inclination angle of the first shear crack depends on the concrete tensile strength and the axial load on the column. For simplicity, we consider that the transverse reinforcement contributes to the shear strength via the formation of a strut-and-tie mechanism with a compression strut angle of $45^{\circ} . V_{s}^{\theta=45^{\circ}}$ is the corresponding shear strength provided by the stirrups for a crack inclination angle of $45^{\circ}$.

For a given shear force $V_{d}$, the shear force that the transverse reinforcement resists can be determined using equation (9). When the shear strength $V_{s}^{\theta=45^{\circ}}$ is greater than the shear force acting on the transverse reinforcement $\left(V_{d}-V_{p}>0\right)$, the transverse reinforcement is in an elastic stage; consequently, the stirrup stress $\left(\sigma_{s v}\right)$ and strain $\left(\varepsilon_{s v}\right)$ can be calculated using equations (10) and (11), respectively:

$$
\begin{aligned}
& V_{s}=V_{d}-V_{p} \geq 0 \\
& \sigma_{s v}=\frac{V_{d}-V_{p}}{Z \cdot \sum \frac{A_{s t}}{S}} \leq f_{y t} \forall \quad V_{s}^{\theta=45^{\circ}} \geq\left(V_{d}-V_{p}\right) \\
& \varepsilon_{s v}=\frac{\sigma_{s v}}{E_{s t}} \quad \forall \quad V_{s}^{\theta=45^{\circ}} \geq\left(V_{d}-V_{p}\right)
\end{aligned}
$$

where $E_{s t}$ is the modulus of elasticity of the steel that the stirrups are made of; $\sum \frac{A_{s t}}{s}$ is the area of the transversal reinforcement per unit length; and $z$ is the lever arm, which can be determined from a moment-curvature analysis to be $z=\frac{M}{A_{s} \sigma_{s}}$ or by using a simplified formulation such as that provided in[24].

However, when the shear strength provided by the stirrups $\left(V_{S}^{\theta=45^{\circ}}\right)$ is insufficient to resist the shear force demand $\left(V_{d}-V_{p}\right)$, the transverse reinforcement with a compression strut angle of $45^{\circ}$ yields. Consequently, the compression strut rotates until it reaches an equilibrium position, if physically feasible (see Figure 6a). Thus, the stirrups further contribute to the resistance mechanism to satisfy the shear demand (see Figure 6b). This mechanism is successively repeated as the shear force increases and the transverse reinforcement yields, thereby contributing to the shear strength. 


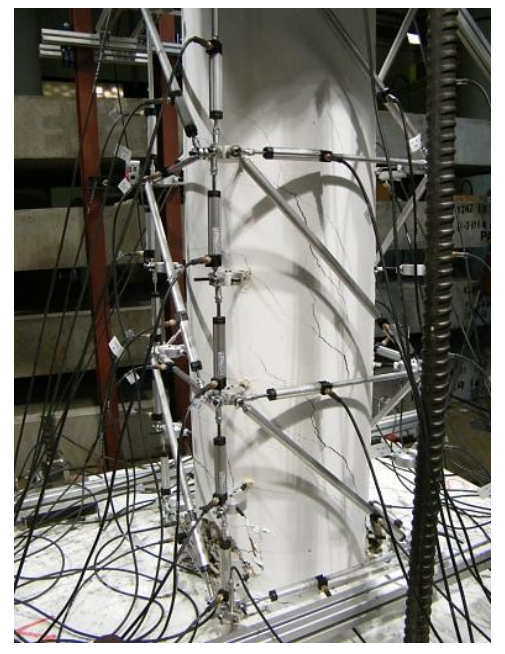

(a) Experimental observation [20]

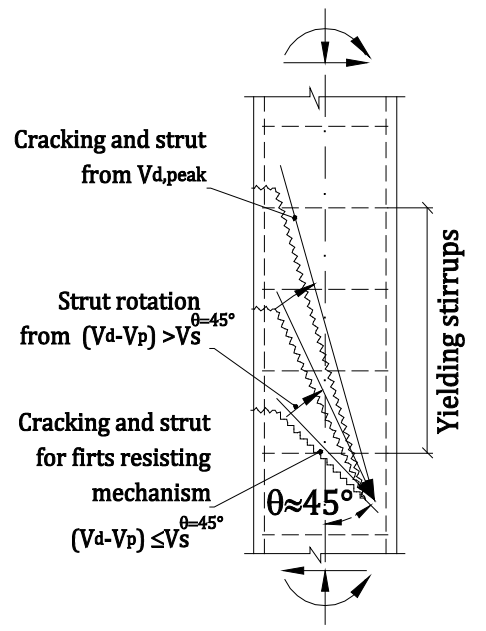

(b) Conceptual model of a strut rotation mechanism

Figure 6 Strut rotation mechanism

The plastic strain is computed using an energy balance, where equation (12) is derived using the approach illustrated in Figure 6. A variable shear crack angle is implicitly considered, and this equation corresponds to a lower bound on the solution based on the plasticity theory.

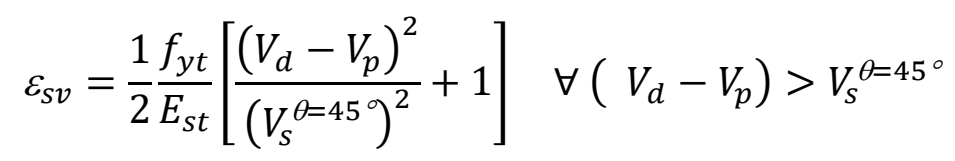

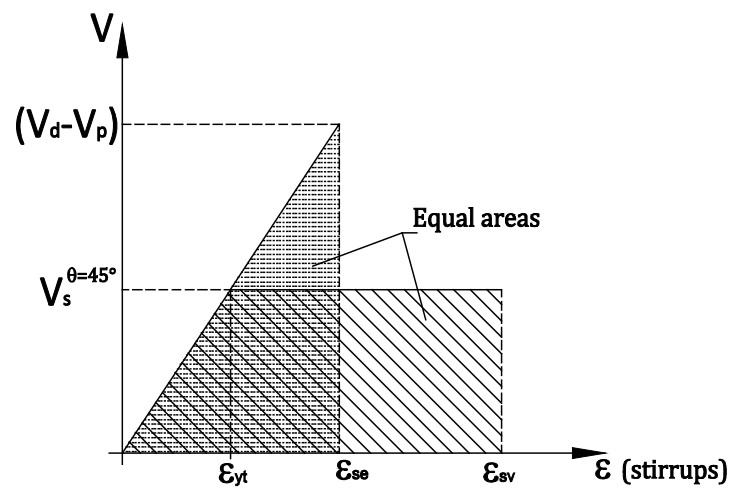

Figure 7 Energy balance approach to estimate the strain in the yielding stirrups

The model developed in [7] is adopted to incorporate the shear strength from the arch effect $\left(V_{p}\right)$ (see Figure 8). Consequently, the shear contribution from the arch effect can be calculated using equation (13):

$$
V_{p}=P \tan \theta_{p}
$$

where $P$ is the axial load, and $\theta_{p}$ is the angle of the compression strut with respect to the column longitudinal axis.
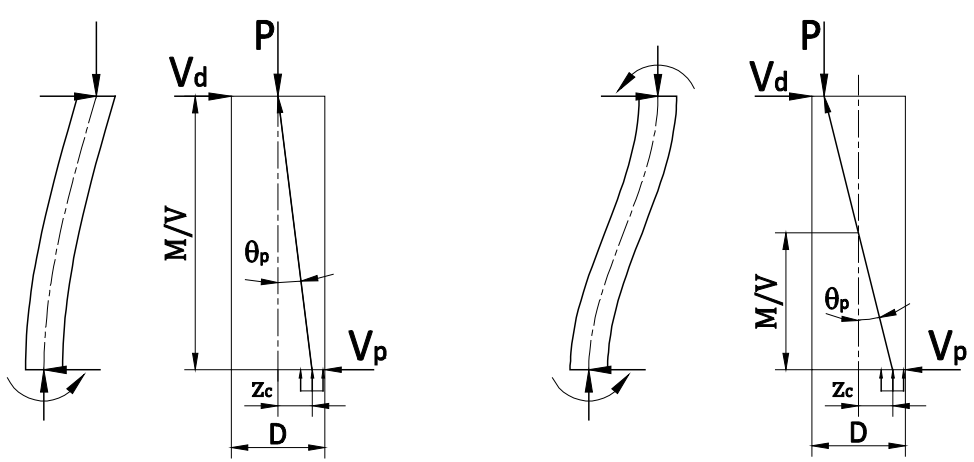

(a) Lateral load in a simple curvature scheme

(b) Lateral load in a double curvature scheme

Figure 8 Axial load contribution to the shear strength (adapted from [7]) 


\section{Effect of shear force on the longitudinal reinforcement and on the moment-curvature relationship}

The aforementioned mechanism in which the rotating struts resist the shear force is equilibrated with the longitudinal reinforcement, thereby increasing the tensile force on the longitudinal reinforcement, as was previously developed by Park and Paulay [10] and has been widely accepted for the structural design codes [25]. Considering the free body diagram shown in Figure 9, the increment in the tensile force $(\Delta T)$ at the longitudinal reinforcement from shear is given by equation (14). The derivation of this force for a general case can be found in:

$$
\Delta T \cdot z=V_{s} \cdot \frac{x}{2}
$$

where $x$ is the distance required to develop $\Delta T$, which is given by equation (15) for stirrups orthogonal to the longitudinal axis of the element:

$$
x=z \cot \theta \cong \frac{V_{s}}{\sum \frac{A_{s t}}{S} f_{y t}}
$$

For members reinforced with circular stirrups or spirals, the $\sum \frac{A_{s}}{s} f_{y t}$ term should be multiplied by a factor of 0.85 to account for the loss of efficiency of the shear reinforcement from the transverse inclination of the stirrups [26].

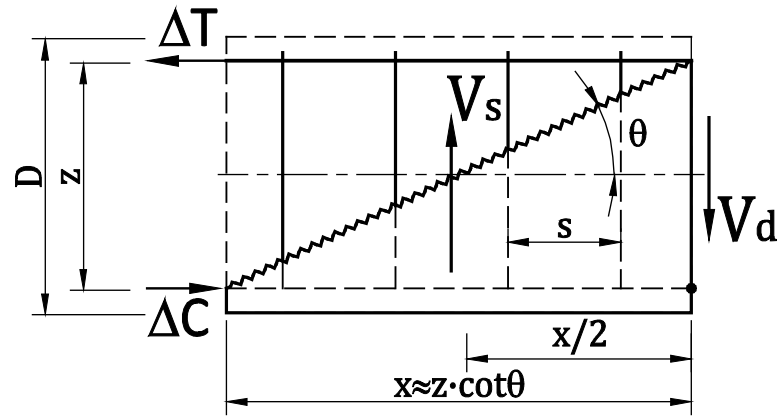

\section{Figure 9 Free body diagram to determine the increment in the force in the longitudinal reinforcement} from the shear force

The product $\Delta T \cdot z$ can be interpreted as an increment in the internal bending moment at the section that is produced by the shear force $\left(\Delta M_{v}\right)$. This product can be expressed as a function of the shear in the transverse reinforcement by substituting equations (9) and (15) into equation (14) to produce equation (16):

$$
\Delta M_{v}=\Delta T \cdot z=\frac{1}{2} \frac{\left(V_{d}-V_{p}\right)^{2}}{\sum \frac{A_{s t}}{S} f_{y t}} \quad \forall V_{d}>V_{p} \quad\left(\begin{array}{l}
16
\end{array}\right) .
$$

Equation (16) shows that the increment in the bending moment from the shear force in the cross section increases quadratically with the contribution of the transverse reinforcement to the shear strength (the demand) and is inversely proportional to the mechanical capacity of the transverse reinforcement provided (the strength).

Therefore, the effective flexural strength $\left(M_{f v}\right)$ can be obtained as the ultimate bending moment capacity $\left(M_{f}\right)$ minus the increment in the bending moment from the shear force, as given in equation (17):

$$
M_{f v}=M_{f}-\Delta M_{v}
$$

Consequently, the moment-curvature relationship of a cross section can be modified by accounting for the concurrent shear force at each moment, as shown in Figure 10a. In principle, the major changes in the diagram can be observed when the contemporary shear force exceeds the shear resistance because of the arch effect $\left(\boldsymbol{V}_{\boldsymbol{d}}>\boldsymbol{V}_{\boldsymbol{p}}\right)$. However, for practical purposes, the modified moment-curvature relationship can be approximated by rotating the entire diagram using equation (18). This simplification produces small errors for 
values of the shear force $\boldsymbol{V}_{\boldsymbol{d}}$ below $\boldsymbol{V}_{\boldsymbol{p}}$, see Figure 10b. The decrease in the curvature of the ductility from shear effects on concrete ductility is also shown.

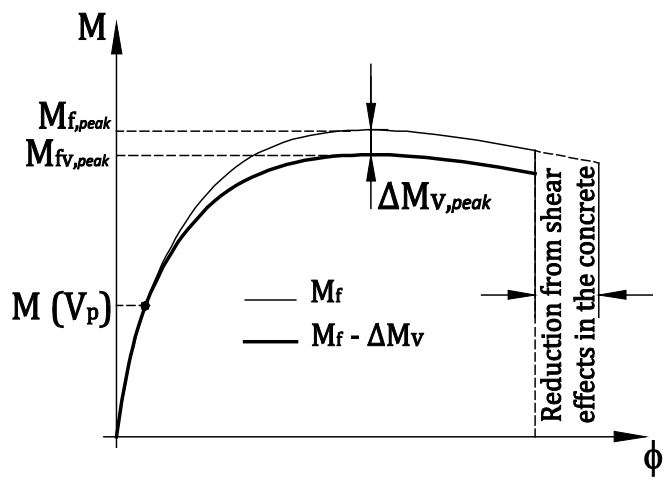

(a) Theoretical curve obtained by changing the response at each moment

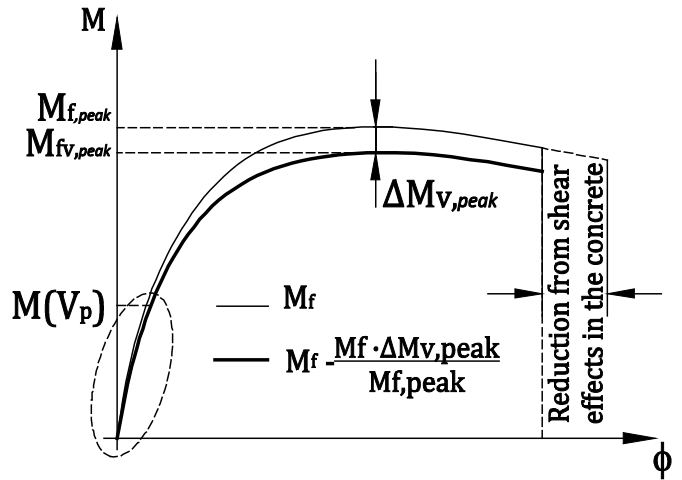

(b) Simplified method, showing rotation of flexure response as a function of $\Delta M_{v, p e a k}$

Figure 10 Moment-curvature relationship considering the effect of the shear force

$$
M_{f v}=M_{f}-\Delta M_{v, \text { peak }} \frac{M_{f}}{M_{f, \text { peak }}}
$$

\subsection{Effect of shear force on plastic hinge length}

In concentrated plasticity models, design recommendations, such as in references $[27,28]$, suggest that plastic hinge formulations with the following format be used [16]:

$$
L_{p}=\left(1-\frac{M_{y}}{M_{u}}\right) L+\alpha_{b} f_{y} d_{b}
$$

where $M_{y}$ is the yielding moment; $M_{u}$ is the ultimate moment; $L$ is the shear span, given by $L=\frac{M}{V} ; \alpha_{b}$ is the coefficient of the strain penetration, with units of $\left[L^{2} / F\right]$; $d_{b}$ is the diameter of the longitudinal bar; and $f_{y}$ is the yield strength of the longitudinal reinforcement. Paulay and Priestley [16] used correlations based on experimental measurements to propose values of 0.08 and $0.022\left[\mathrm{~mm}^{2} / \mathrm{N}\right]$ for $\left(1-\frac{M_{y}}{M_{u}}\right)$ and $\alpha_{b}$, respectively [29]. Priestley and Park [29] explained that the plastic hinge length is increased by the shift in the tension (or the spread of plasticity). Therefore, for calibration purposes, a function of the section depth was added to quantify this increase and a shear strength with a fixed $45^{\circ}$ shear crack was assumed, which was consistent with experimental observations of the tested columns used in calibration. Notice that most of these tested columns had suitable shear strength capacities for a shear crack that was approximately equal to $45^{\circ}$; hence, it was observed an elastic behavior of the transverse reinforcement in the plastic hinge by shear forces. Therefore, Priestley and Park did not find a section depth correlation [29]. Given the analysis presented above and Figure 11, the following expression can be derived using equations (16), (17) and (19):

$$
L_{p}=\left(1-\frac{M_{y}}{M_{u}}\right) L+\alpha_{b} f_{y} d_{b}+\frac{1}{2} \frac{\left(V_{d}-V_{p}\right)^{2}}{V_{d} \cdot \sum \frac{A_{s t}}{S} f_{y t}} \forall V_{d}>V_{p} \quad\left(\begin{array}{l}
20
\end{array}\right) .
$$

Equation (20) shows that the shear force results in the lengthening of the plastic hinge when there is a demand for the contribution of the transverse reinforcement. Therefore, this term serves to quantify the increment in the plastic length from shear effects for shear crack angles below $45^{\circ}$. 


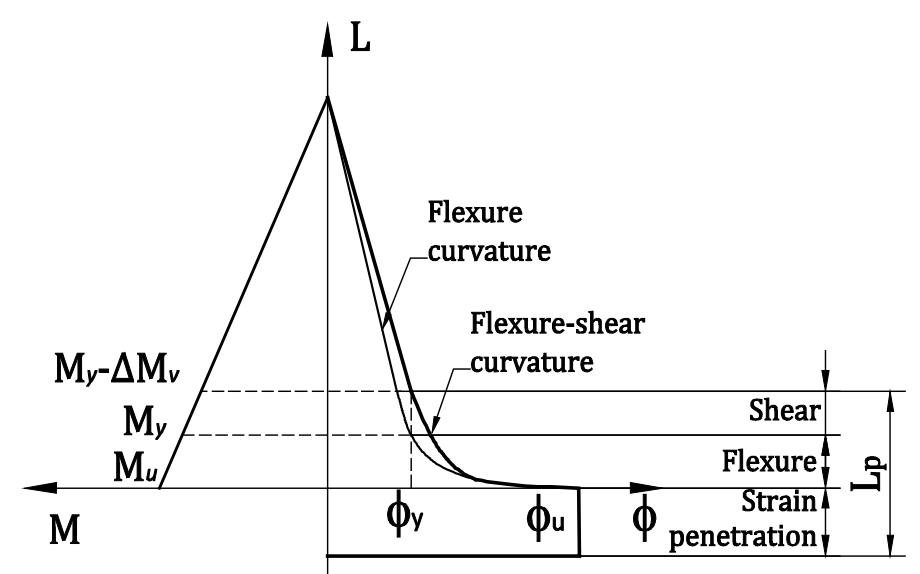

Figure 11 Effect of shear force on plastic hinge length

\section{Numerical implementation of analytical approach into lumped plasticity models}

In the previous sections, equations were presented to calculate the effect of the unidirectional and bidirectional shear forces on the concrete stress-strain diagram, the moment-curvature diagrams and the plastic hinge length. All of these equations depend on $V_{d}$, which is related to the resisting bending moment in the column $\left(M_{f v}\right)$ through the shear span (M/L). The forces, $V_{d}$ and $M_{f v}$, are interdependent; therefore, the problem has to be solved iteratively. However, only two or three iterations are required in most cases. Figure 12 shows a flow diagram of the numerical implementation of the formulation developed.

The displacement at the load application point is the sum of the flexural displacement $\left(\Delta_{f}\right)$, the displacement from the shear $\left(\Delta_{S}\right)$ and the displacement from the strain penetration of the longitudinal rebar $\left(\Delta_{\theta}\right)$, as given by equation (21):

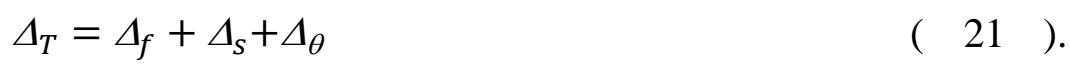

Using the model developed by Priestley and Park [60], the displacements from the flexure and strain penetration $\left(\Delta_{f}+\Delta_{\theta}\right)$ can be calculated from the sum of the elastic $\left(\Delta_{y}\right)$ and the plastic $\left(\Delta_{p}\right)$ displacement components:

$$
\Delta_{f}+\Delta_{\theta}=\Delta_{y}+\Delta_{p}
$$

The elastic and plastic components can be calculated from the corresponding portion of the curvature:

$$
\begin{gathered}
\Delta_{y}=\phi_{y} \frac{L_{e}{ }^{2}}{3} \\
\Delta_{p}=\phi_{p} L_{p}\left(L_{e}-\frac{L_{p}}{2}\right)
\end{gathered}
$$

where $\phi_{y}$ is the yielding curvature; $\phi_{p}$ is the plastic portion of the curvature; $L_{p}$ is the equivalent plastic hinge length from equation (20); and $L_{e}$ is the column length $(L)$ plus the length corresponding to the strain penetration from equation (26). The shear displacement $\left(\Delta_{s}\right)$ does not appear because it is incorporated into the model for the plastic hinge length.

$$
\begin{gathered}
\phi_{p}=\phi-\phi_{y} \quad \forall \phi>\phi_{y} \\
L_{e}=L+\alpha_{b} f_{y} d_{b}
\end{gathered}
$$




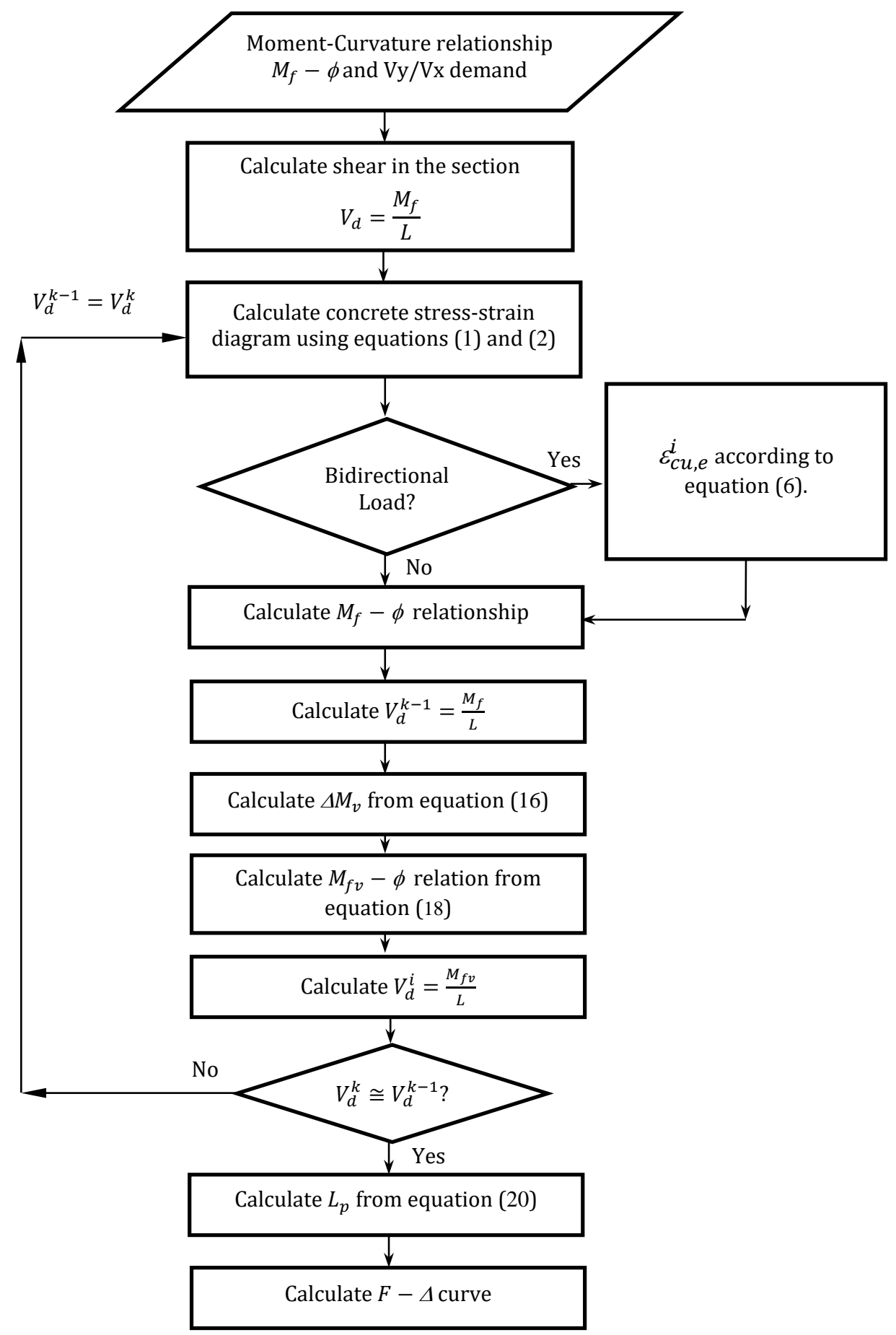

Figure 12 Flow diagram to determine the effects of shear on the capacity curve

\section{Verification of the analytical model developed}

\subsection{Description of experimental program}

The results of the recommendations developed were verified using the results of experiments performed by Osorio on reinforced concrete columns with circular cross sections under unidirectional and bidirectional lateral loads [9]. All of the columns had a 350-mm diameter, and the lateral loads were applied at a distance of $1.5 \mathrm{~m}$ from the fixed column base in a cantilever configuration. The typical test configuration is shown in Figure 13.

The longitudinal reinforcement consisted of 12 bars, each of which had a $\phi 16 \mathrm{~mm}$ diameter. The transverse reinforcement had a clear cover of $19 \mathrm{~mm}$ and consisted of 6-mm diameter hoops with two different spacings; two columns had a spacing of $s=300 \mathrm{~mm}$, whereas the other four columns had a spacing of $s=200 \mathrm{~mm}$, as shown in Figure 14. The transverse reinforcement was designed to sustain flexure-shear failure. Note that the transversal reinforcement considered is representative of the design of many existing columns in Europe that comply with old code provisions in low to moderate seismic areas.

The compressive strength of the cylindrical concrete specimens was $f_{c}=57.3 \mathrm{MPa}$, and the concrete modulus of elasticity was $E_{c}=36992 \mathrm{MPa}$. The steel yield strengths of the longitudinal and transverse reinforcements 
were $f_{y(0.2 \%)}=546$ and $507 \mathrm{MPa}$, respectively. The steel modulus of elasticity was $E_{s}=194 G P a$ for the longitudinal reinforcement and $199 \mathrm{GPa}$ for the stirrups. All of the mechanical properties of the materials were obtained from standard tests.

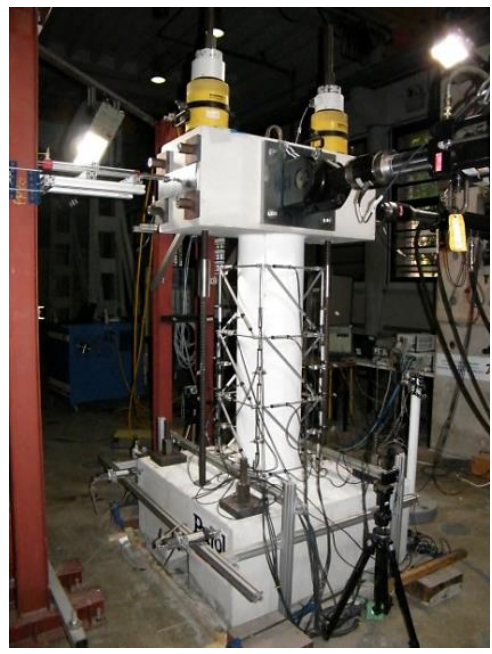

Figure 13 Test configuration

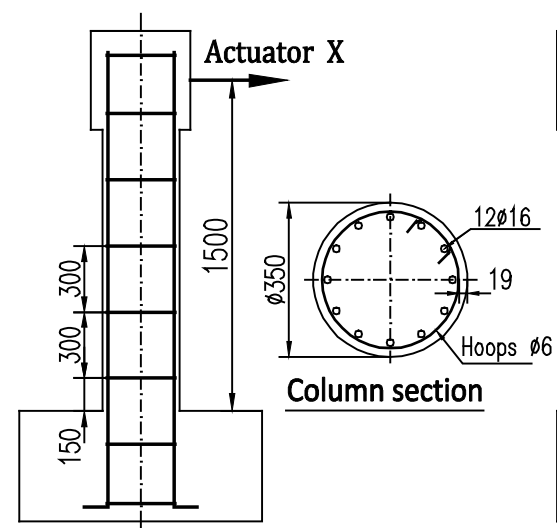

Type A - Hoops @300

[Elevation X)

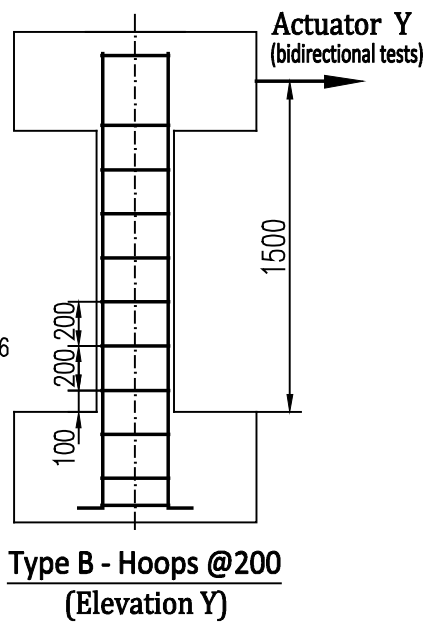

(Elevation $\mathrm{Y}$

Figure 14 Details of geometry and reinforcement of experimental models

The column tests were performed under a quasi-static load by introducing incremental load cycles under a constant axial load (see Figure 15a). For the bidirectional tests, a trajectory with a quadrifolium pattern was chosen with equal amplitudes in both directions (see Figure 15b). This loading path can be considered to be an orthogonal path, as shown in reference [6]. The parameters for each test, that is, the axial load, the stirrups spacing and the loading type (uni- or bidirectional), are given in Table 1 . The tests were terminated when the lateral load was decreased by $20 \%$ with respect to the maximum resisted load.

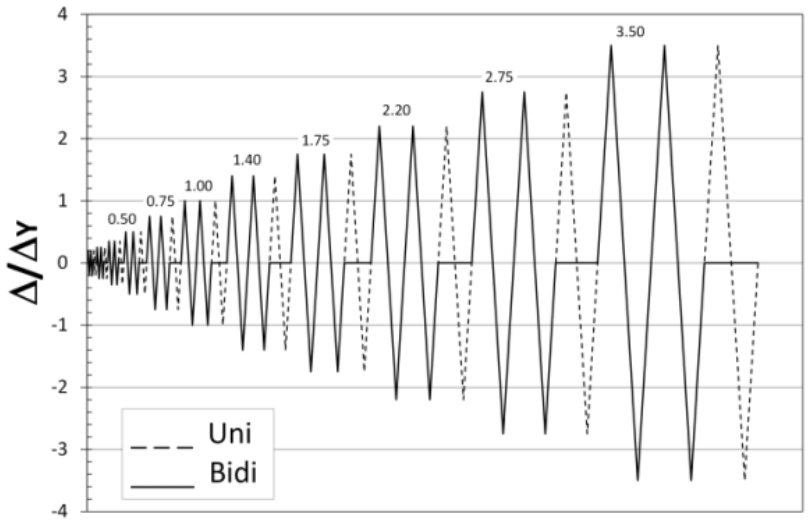

(a) Loading histories

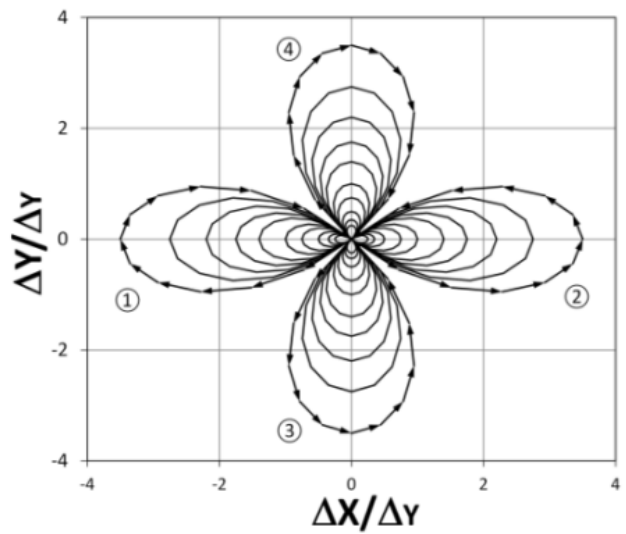

(b) Bidirectional loading pattern

Figure 15 Loading histories and bidirectional loading pattern

The results from both the unidirectional and bidirectional experiments and the tests on the columns with an axial loading of $1100 \mathrm{kN}$ are presented below; the complete test results are presented in reference [9].

Table 1 Experimental model parameters [20]

\begin{tabular}{cccc}
\hline $\begin{array}{c}\text { Column } \\
\text { No. }\end{array}$ & $\begin{array}{c}\text { Axial load } \\
{[\mathbf{k N}]}\end{array}$ & $\begin{array}{c}\text { s } \\
{[\mathbf{m m}]}\end{array}$ & $\begin{array}{c}\text { Type of lateral } \\
\text { load }\end{array}$ \\
\hline U1-945-300-N & 945 & 300 & Unidirectional \\
B2-945-300-N & 945 & 300 & Bidirectional \\
U3-1100-200-N & 1100 & 200 & Unidirectional \\
U4-550-200-N & 550 & 200 & Unidirectional \\
B5-1100-200-N & 1100 & 200 & Bidirectional \\
B6-550-200-N & 550 & 200 & Bidirectional \\
\hline
\end{tabular}




\subsubsection{Column U3-1100-200}

Column U3 exhibited cracks normal to the longitudinal axis with an approximate spacing of $80 \mathrm{~mm}$, even for cycles with an amplitude of $0.75 \Delta \mathrm{y}$. For the next highest amplitude $(1.0 \Delta \mathrm{y})$, flexural cracks propagated in a diagonal direction at an angle of approximately $45^{\circ}$ to the longitudinal axis. For $1.4 \Delta \mathrm{y}$, the spalling of the concrete cover at the column base was observed, and new diagonal cracks appeared at angles between $35^{\circ}$ and $40^{\circ}$. In addition, vertical cracks appeared in subsequent cycles. For the cycle with an amplitude of $1.75 \Delta \mathrm{y}$, new diagonal cracks were observed at an angle of $30^{\circ}$ to the longitudinal axis, which extended into the tension zone. The test was terminated after the completion of a third cycle with an amplitude of $2.2 \Delta \mathrm{y}$, when the lateral load decreased by $20 \%$ with respect to the maximum resisted load because of the spalling of concrete cover followed by the buckling of a longitudinal reinforcement bar at a distance between 200 and $450 \mathrm{~mm}$ from the column base (see Figure 16). The shear force-displacement curve of this column is plotted in Figure 17.

\subsubsection{Column B5-1100-200}

In column B5, flexural cracks were observed even for cycles with amplitudes of $0.75 \Delta \mathrm{y}$. For an amplitude of $1.0 \Delta \mathrm{y}$, crushing of concrete occurred near the base, cracks appeared parallel to the column axis and the spalling of thin concrete layers was observed. During cycles with an amplitude of $1.40 \Delta \mathrm{y}$, flexural cracks propagated diagonally and connected rapidly with the vertical cracks, forming a mean angle of approximately $20^{\circ}$. The test was terminated upon completion of the cycles with an amplitude of $1.75 \Delta \mathrm{y}$ when the lateral load decreased by more than $20 \%$ of the maximum resisted load, following concrete spalling and buckling of the longitudinal bars between $100 \mathrm{~mm}$ and $400 \mathrm{~mm}$ away from the column base (see Figure 18). The shear force-displacement and curves for the X-shear force vs. the Y-shear force for this column are shown in Figure 19 and Figure 20, respectively.

An envelope curve was obtained for each shear force-displacement curve, as shown in Figure 21. Figure 22 shows the experimentally obtained envelopes for both the unidirectional and bidirectional tests for the three axial loads studied.

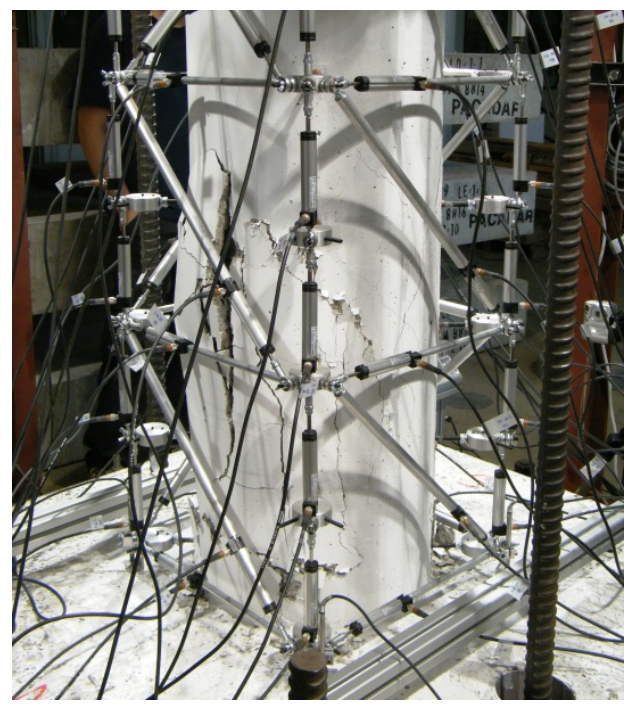

Figure 16 Damage observed during the final load cycle for column U3-1100-200

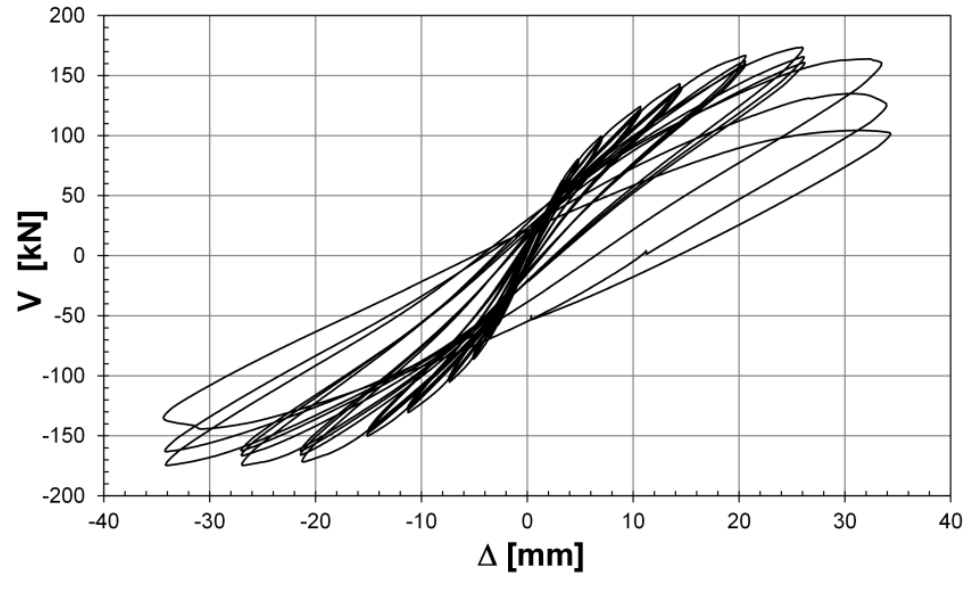

Figure 17 Shear force-displacement for column U3-1100-200 


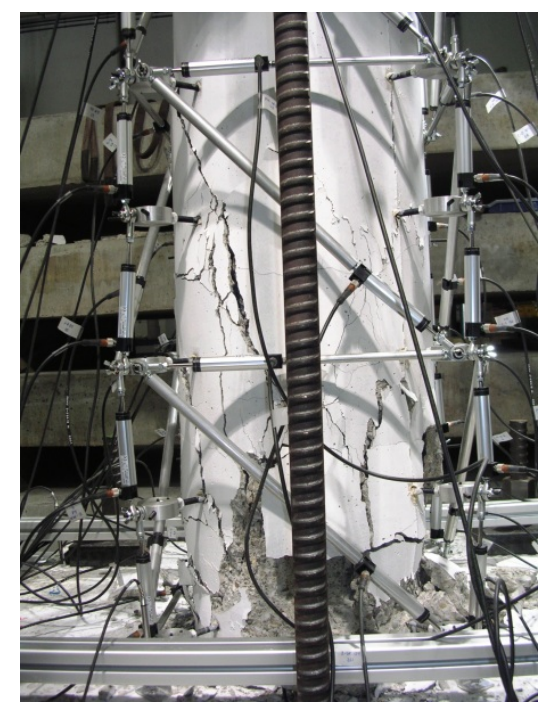

Figure 18 Damage observed during the final load cycle for column B5-1100-200

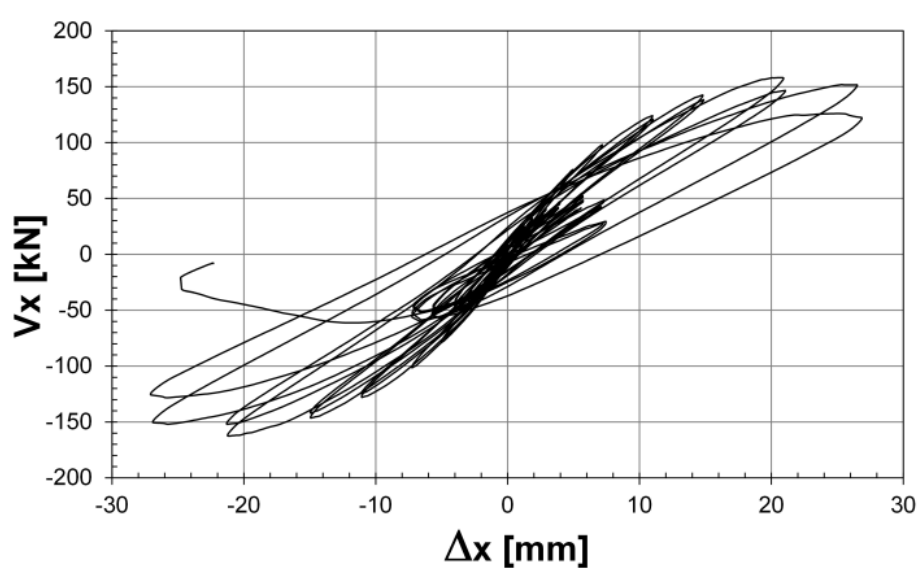

(a) X-direction

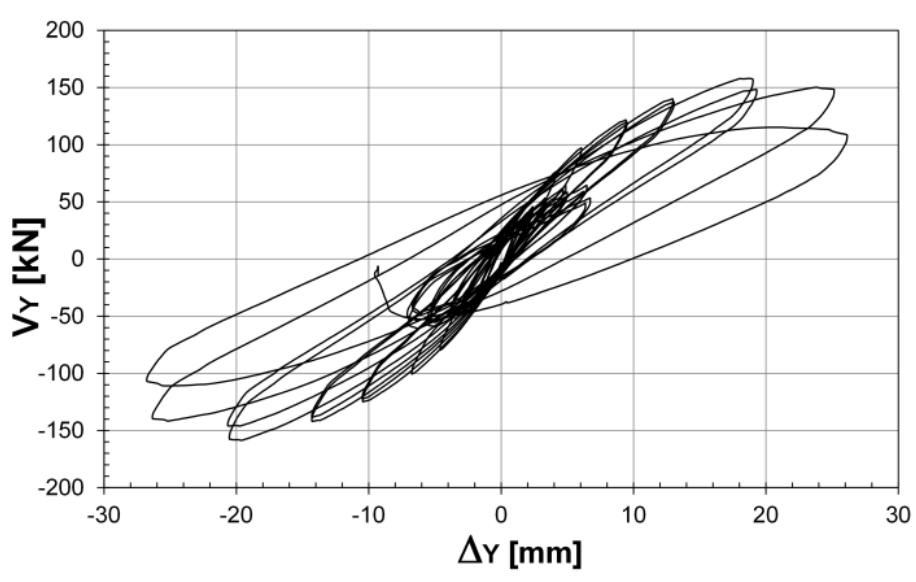

(b) Y-direction

Figure 19 Shear force-displacement curve for column B5-1100-200

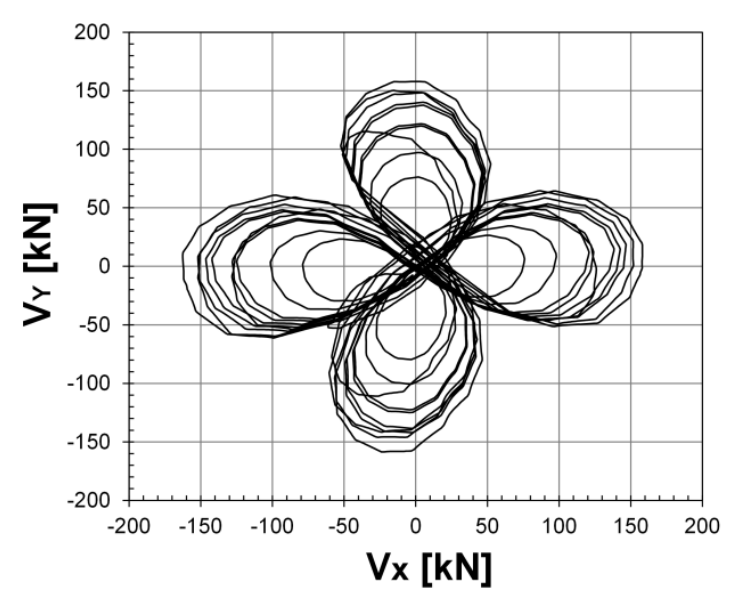

Figure $20 \mathrm{X}$-shear force vs. Y-shear force for column B5-1100-200

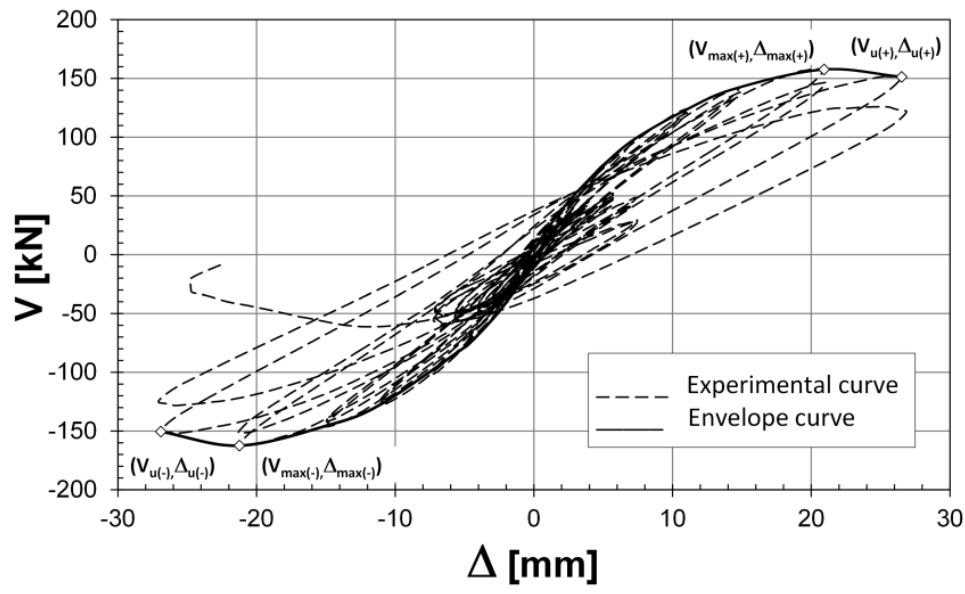

Figure 21 Criteria for defining envelope curves 


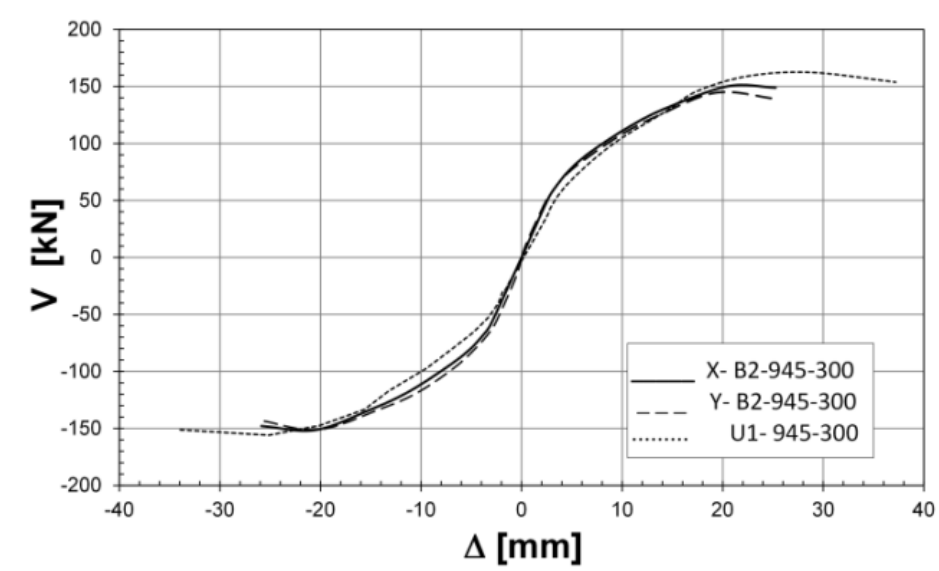

(a) Tests with axial force $\mathrm{N}=945 \mathrm{kN}$

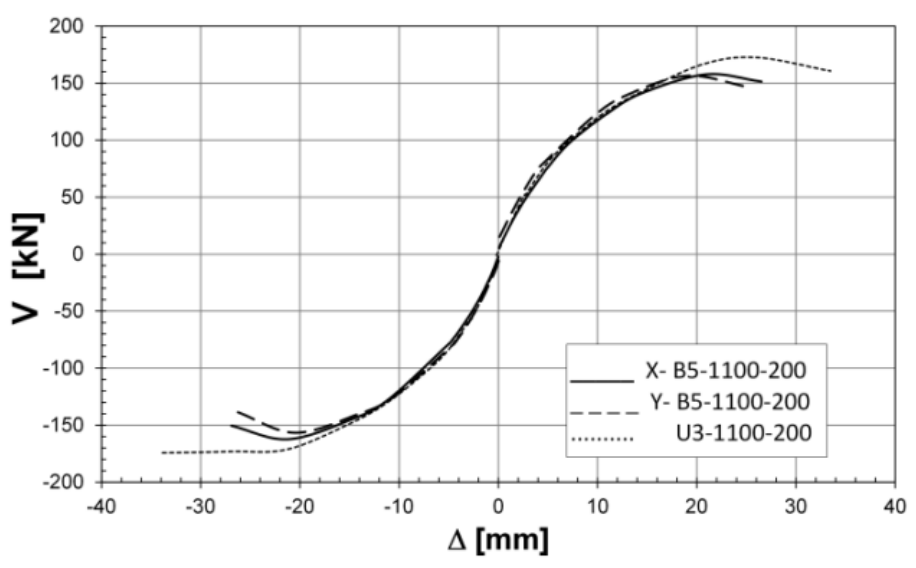

a) Tests with axial force $\mathrm{N}=1100 \mathrm{kN}$

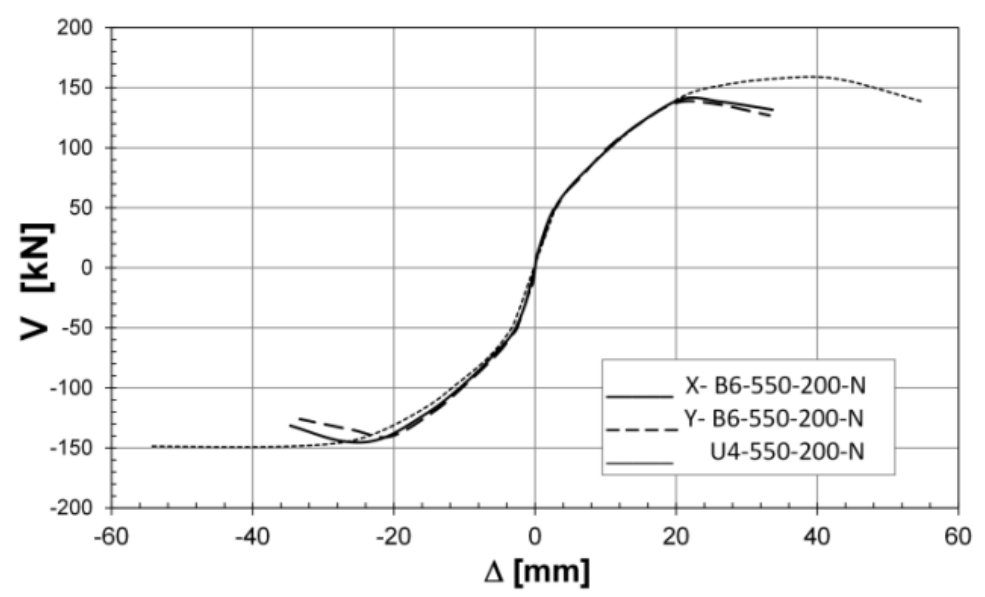

(c) Tests with axial force $\mathrm{N}=550 \mathrm{kN}$

Figure 22 Results from unidirectional and bidirectional tests

\subsection{Key aspects considered in the numerical analyses}

For each column type, analyses were performed with and without shear effects. For the analyses without shear effects, the cross section considered was located at the column base, i.e., a hoop spacing of s/2 was used in accordance with the experimental model. In the analyses with shear effects, the cross section was situated at a distance of $\mathrm{D} / 2$ from the column base for a hoop spacing of $\mathrm{s}$. In all of the cases considered, the lateral load capacity was calculated for a shear span (M/V) corresponding to the cross section (see Figure 23).

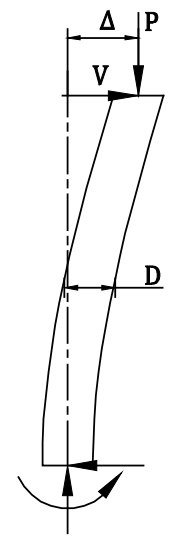

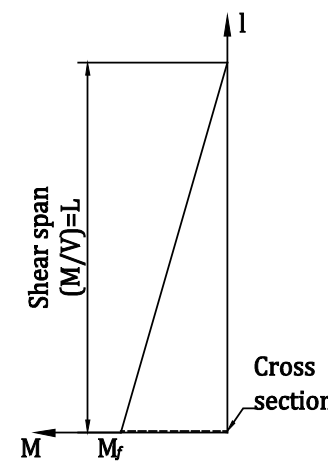

a) Without shear effects

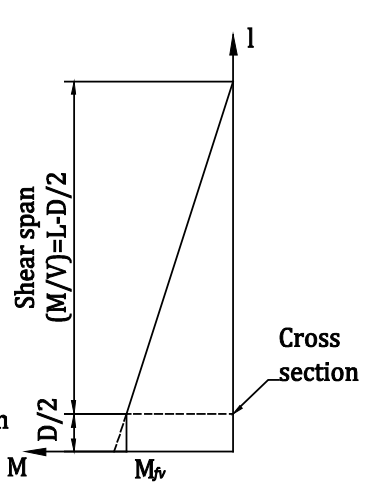

b) With

shear effects

Figure 23 Models used in analyses

The parameters used by Mander et al. [11] were used to determine the stress-strain relationship of the confined concrete. The ultimate compressive concrete strain was the lower of the values used by Mander et al. [11] and the strain in the softening branch at the stress at $50 \%$ of the peak strength. An elastic-plastic model with a yielding strength of $1.1 f_{y(0.2 \%)}$ and a hardening modulus of $0.005 E_{s}$ was used for the reinforcing steel. The effects of the shear forces were evaluated using the flow diagram shown in Figure 12, and the load-displacement curve was obtained following the procedure described in the previous section. The analyses were used to find the first failure of the confined concrete fibers. 


\subsection{Analytical concrete stress-strain, plastic length and force-displacement curves with shear effects}

Figure 24 shows the analytical concrete stress-strain curves with shear effects. For the three axial loads $P=550$, 1100 and $945 k N$, the maximum shear force developed in the column produced yielding in the transverse reinforcement of the plastic hinge. Thus, the confinement stress acting on the concrete in the direction of the lateral force was estimated to be null. Therefore, the compression strength and the ultimate strain of the confined concrete was calculated for a biaxial stress state $\left(f_{c c}\left(0.0, \sigma_{e, y}\right) ; \varepsilon_{c c}\left(0.0, \sigma_{e, y}\right)\right)$. For bidirectional loading, Figure 24 shows the effects of the lateral strains produced by shear forces in the orthogonal direction.

Figure 25 shows the moment-curvature diagrams for the columns investigated at three axial load levels. For the curves with shear effects, the resisting moment from the tension shift $\left(\Delta M_{v}\right)$ decreased. The concrete deformation capacity of the bidirectionally loaded columns also decreased (with bi-shear).

The analytical calculations of the plastic hinge lengths of the columns studies are given in Table 2. In the first column of Table 2, the numbers in the parentheses represent the contribution of shear effects using the equation originally derived by Priestley and Park [29], i.e., $(1-\mathrm{My} / \mathrm{Mu}=0.08 \mathrm{~L})=120 \mathrm{~mm}$ and $\alpha_{b} f_{y b} d_{b}=211 \mathrm{~mm}$. The numbers in the parentheses in the second column represent the contribution from the shear shift as estimated by the developed model $\left(\delta \mathrm{Lp}_{\mathrm{s}}\right)$. Considering shear effects for the tested columns caused the analytical plastic hinge lengths to increase by approximately $50 \%$ to $70 \%$ over the plastic hinge length calculated without shear effects.

The shear force-displacement curves were obtained using the previously obtained moment-curvature diagrams and analytical plastic lengths. The collapse condition of the analytical results was attained when the confined concrete fiber reached the ultimate strain according to the stress-strain curve with shear effect diagram of Figure 24. The resulting capacity curves are shown in Figure 26. The resisting shear capacity decreased compared to that calculated without shear effects. The section at which failure theoretically occurred was at a distance of D/2 from the column base, which was in agreement with the experimental observations. The displacement capacity of the columns under bidirectional shear forces with respect to the unidirectional shear force also decreased for the three cases investigated: this decrease in the ductility was more significant than the decrease in the shear resisting capacity.

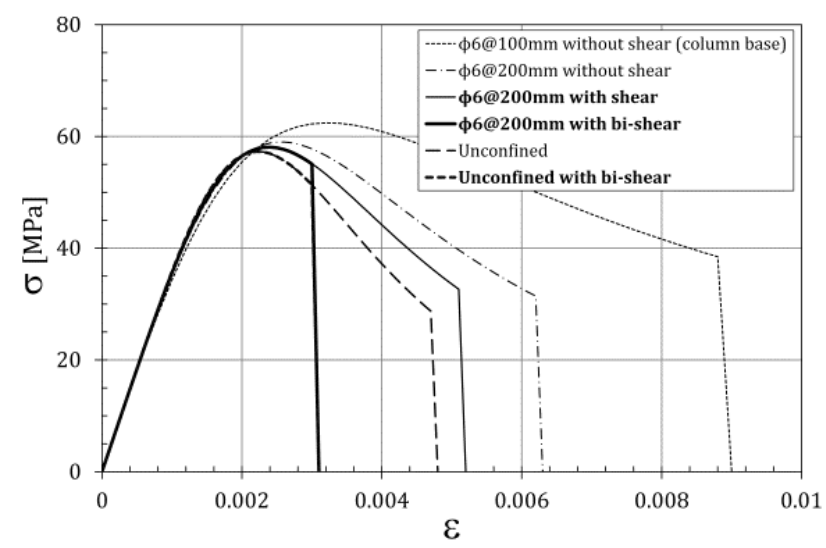

(a) Axial force $\mathrm{P}=550 \mathrm{kN}$

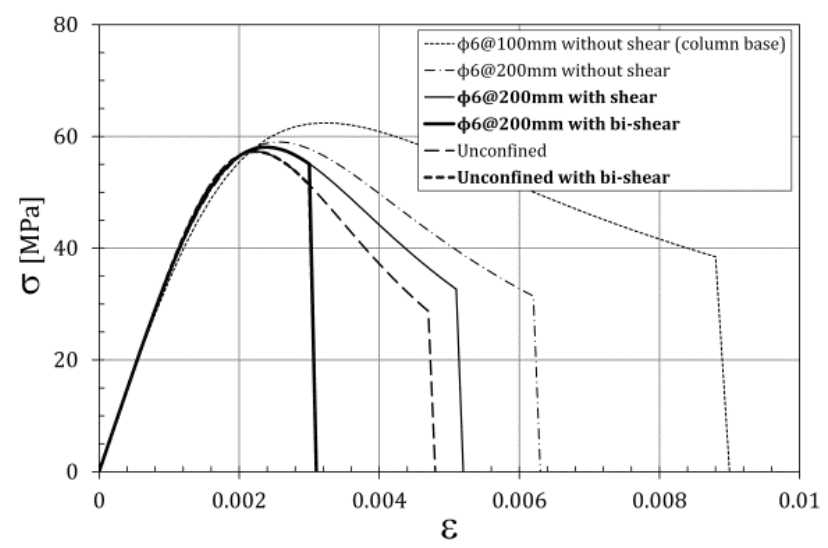

(b) Axial force $\mathrm{P}=1100 \mathrm{kN}$

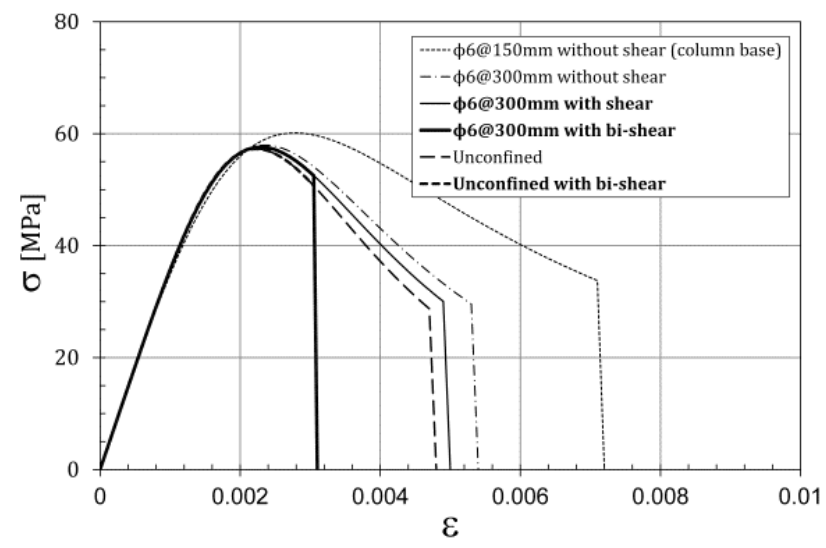

(c) Axial force $\mathrm{P}=945 \mathrm{kN}$

Figure 24 Concrete stress-strain curves with shear effects 


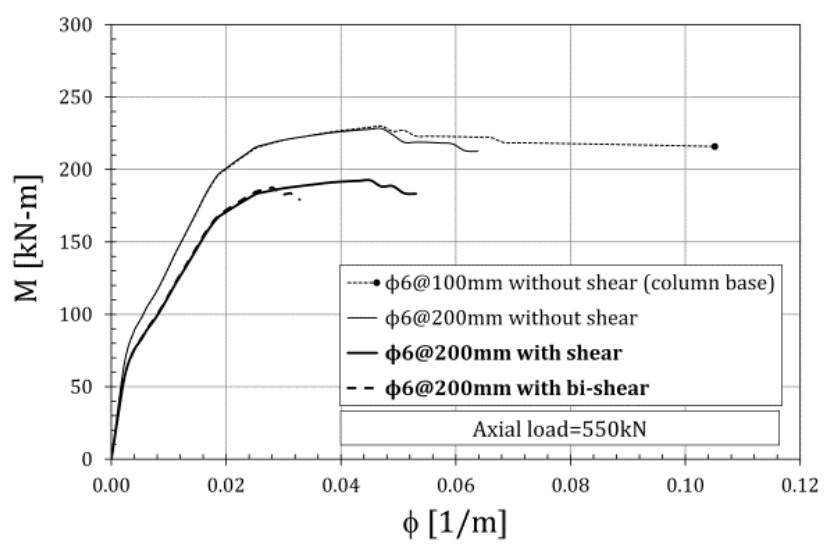

(a) Axial force $\mathrm{P}=550 \mathrm{kN}$

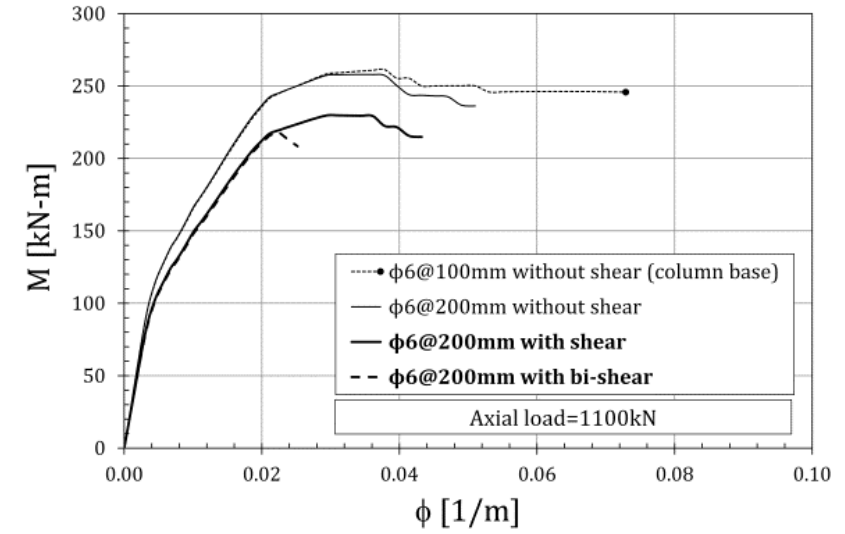

(b) Axial force $\mathrm{P}=1100 \mathrm{kN}$

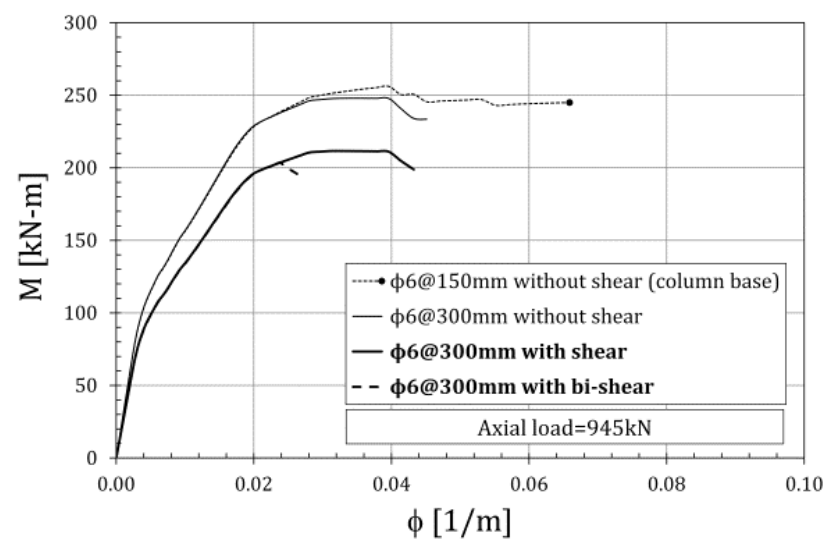

(c) Axial force $\mathrm{P}=945 \mathrm{kN}$

Figure 25 Analytical moment-curvature diagrams considering the effects of unidirectional and bidirectional shear forces

Table 2 Analytical plastic length with and without considering shear effects

\begin{tabular}{l|lll}
\hline \multirow{2}{*}{ Column } & \multicolumn{3}{|c}{ Analytical Plastic length } \\
\cline { 2 - 4 } & $\begin{array}{c}\text { Priestley \& Park } \\
\text { equation [29] } \\
{[\mathbf{m m}]}\end{array}$ & $\begin{array}{c}\text { Developed equation } \\
(20)\end{array}$ & Ratio \\
[mm] & \\
\hline U4-550-200-N & $331(120+211)$ & $567\left(\delta \mathrm{Lp}_{\mathrm{s}}=236\right)$ & 1.71 \\
B6-550-200-N & 331 & $555(224)$ & 1.68 \\
\hline U3-1100-200-N & 331 & $486(155)$ & 1.47 \\
B5-1100-200-N & 331 & $500(169)$ & 1.51 \\
\hline U1-945-300-N & 331 & $554(223)$ & 1.67 \\
B2-945-300-N & 331 & $558(272)$ & 1.69 \\
\hline
\end{tabular}

Figure 27 to Figure 29 compare the analytical and experimental shear-displacement curves for different axial loads. The experimental curve is the envelope of the cyclic test response. The analytical curves with shear effects reproduced the experimentally observed behavior for both unidirectional and bidirectional shear forces. Accurate peak loads and ultimate displacements were also obtained (see Table 3). 


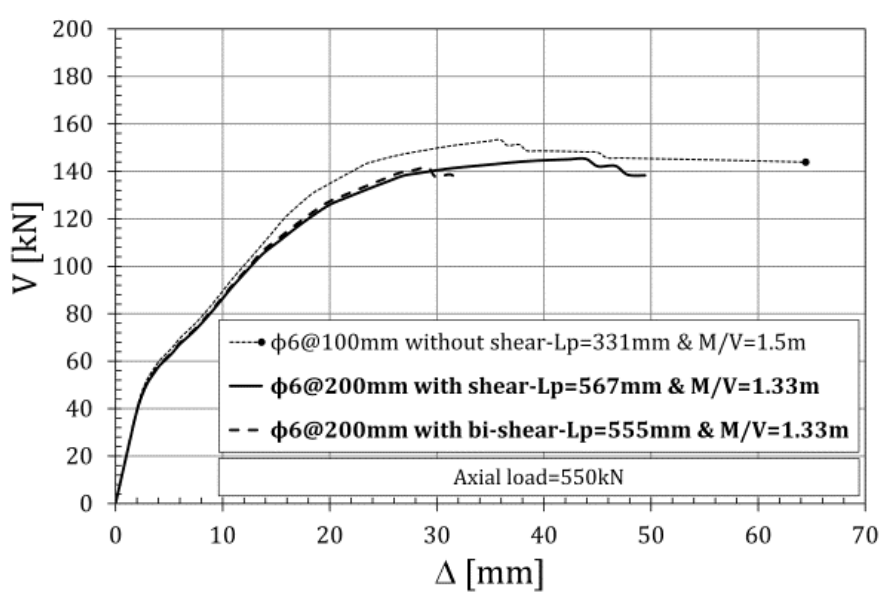

(a) Axial force $\mathrm{P}=550 \mathrm{kN}$

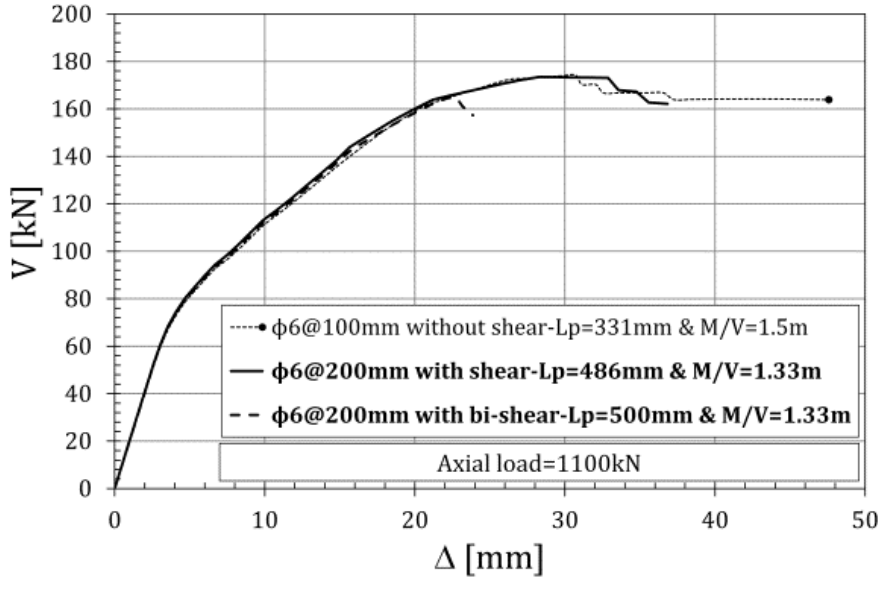

(b) Axial force $\mathrm{P}=1100 \mathrm{kN}$

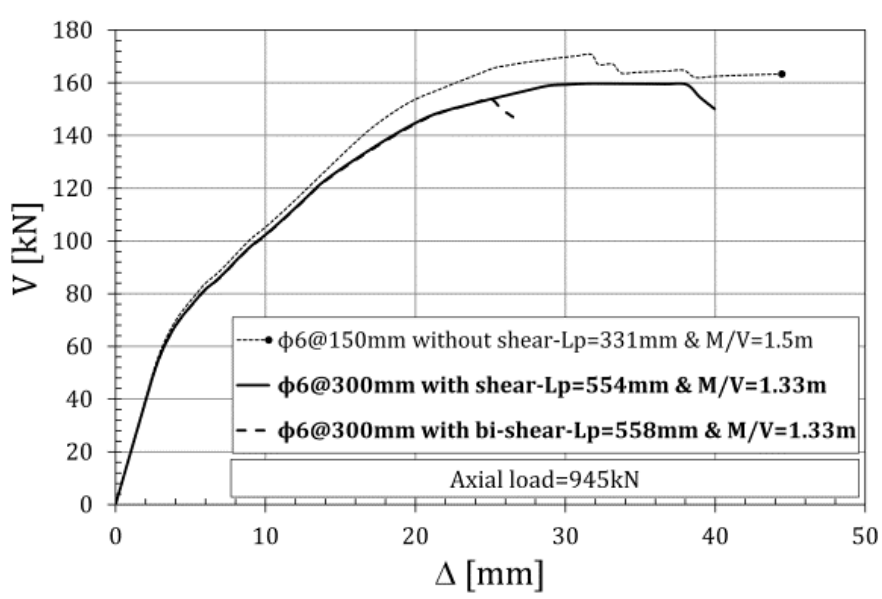

(c) Axial force $\mathrm{P}=945 \mathrm{kN}$

Figure 26 Analytical shear force-displacement curves, including the effects of unidirectional and bidirectional shear forces

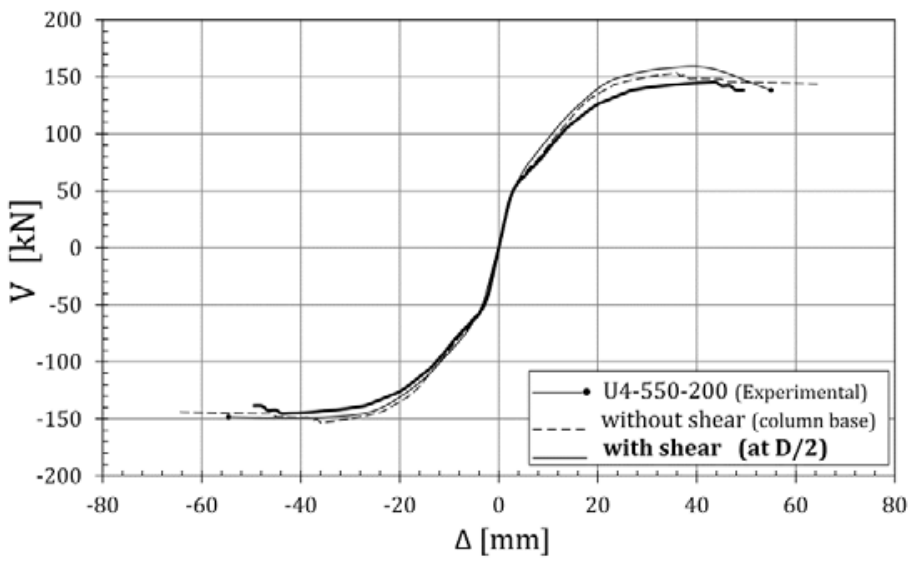

(a) Unidirectional loading

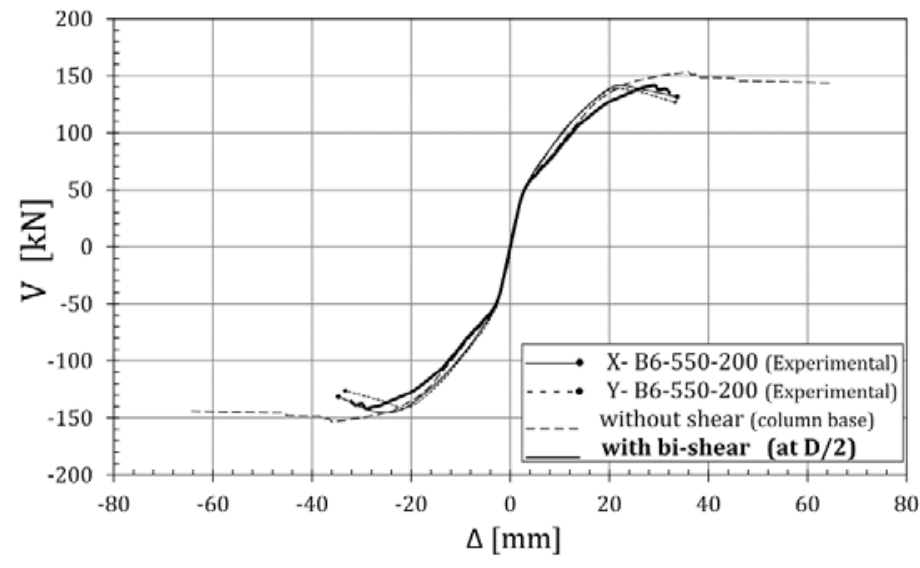

(b) Bidirectional loading

Figure 27 Analytical and experimental shear force-displacement for columns with an axial load $\mathbf{P =} 550$ kN 


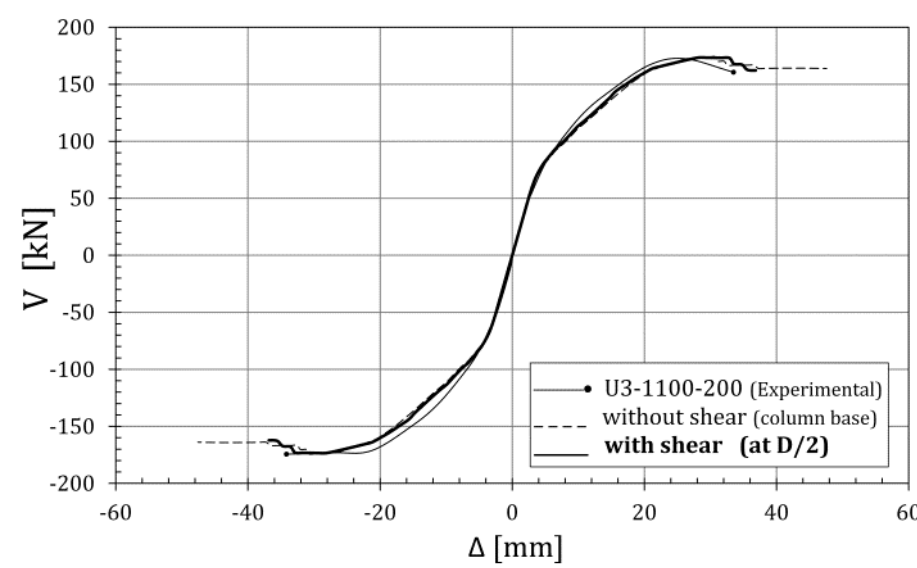

(a) Unidirectional loading

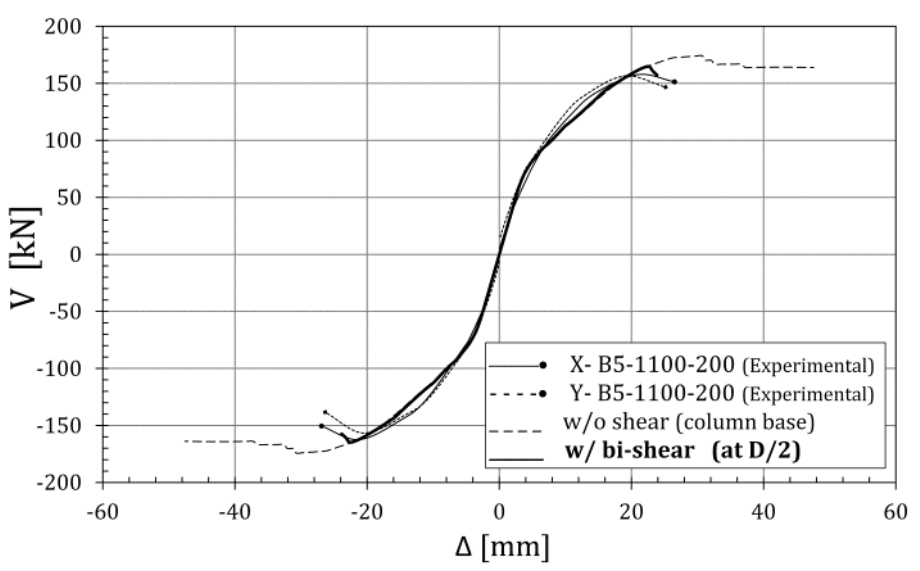

(b) Bidirectional loading

Figure 28 Analytical and experimental shear force-displacement for columns with an axial load $P=1100$ kN

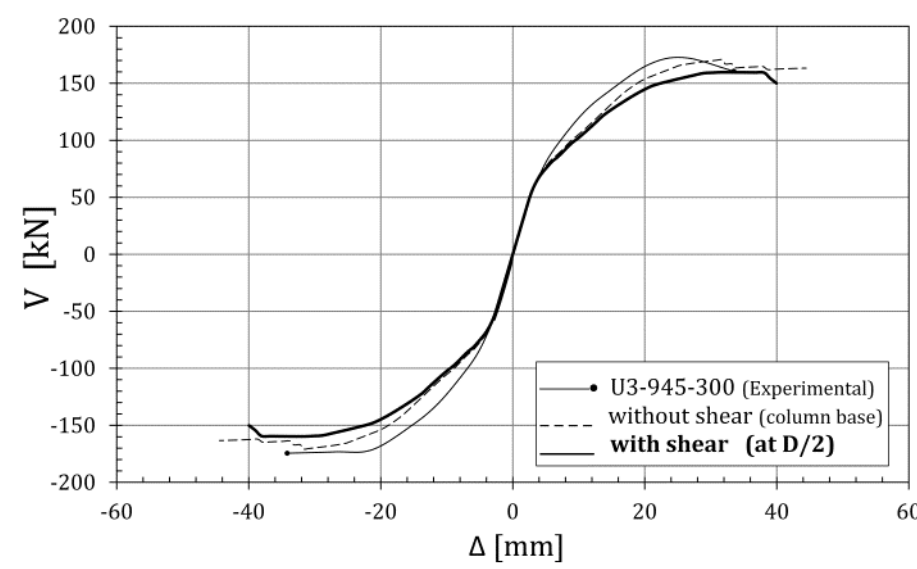

(a) Unidirectional loading

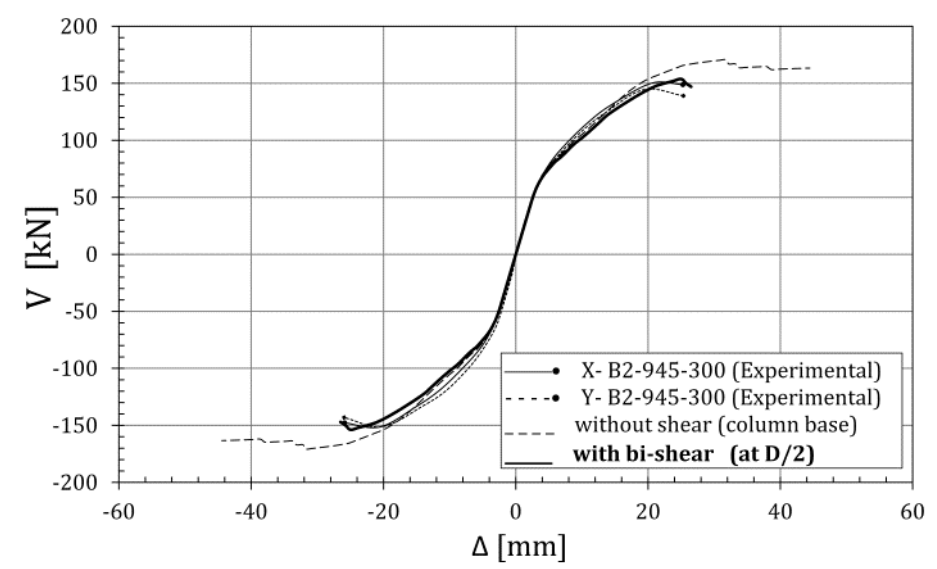

(b) Bidirectional loading

Figure 29 Analytical and experimental shear force-displacement for columns with an axial load N=945 $\mathbf{k N}$

Table 3 Comparison of characteristic values of shear force-displacement curves

\begin{tabular}{cccccc}
\hline \multirow{2}{*}{ Column } & $\begin{array}{c}\text { Experimental } \\
\text { /Analytical (with shear) }\end{array}$ & $\begin{array}{c}\boldsymbol{V}_{\text {peak }} \\
{[\mathbf{k N}]}\end{array}$ & A/E & $\begin{array}{c}\Delta_{\boldsymbol{u}}{ }^{\mathrm{a}, \mathrm{b}} \\
{[\mathbf{m m}]}\end{array}$ & A/E \\
\hline \multirow{2}{*}{ U4-550-200-N } & Experimental & 153.3 & & 54.8 & \\
& Analytical & 145.3 & $(0.95)$ & 49.4 & $(0.90)$ \\
B6-550-200-N & Experimental & 140.1 & & 33.7 & \\
& Analytical & 141.6 & $(1.01)$ & 32.1 & $(0.95)$ \\
\hline U3-1100-200-N & Experimental & 172.8 & & 33.8 & \\
& Analytical & 173.5 & $(1.01)$ & 36.8 & $(1.09)$ \\
B5-1100-200-N & Experimental & 158.3 & & 26.2 & \\
& Analytical & 164.8 & $(1.05)$ & 23.9 & $(0.91)$ \\
\hline U1-945-300-N & Experimental & 159.2 & & 35.5 & \\
& Analytical & 159.7 & $(1.01)$ & 39.9 & $(1.12)$ \\
B2-945-300-N & Experimental & 149.3 & & 25.6 & \\
& Analytical & 153.8 & $(1.03)$ & 26.5 & $(1.03)$ \\
\hline
\end{tabular}

${ }^{\text {a }}$ Experimental $\Delta_{\boldsymbol{u}}$ is defined according to Figure 21

b Analytical $\Delta_{\boldsymbol{u}}$ corresponds to first failure of confined concrete fibers

\section{Conclusions}

The mechanical behavior of reinforced concrete columns under lateral loads is very complex and becomes even more complex with multidirectional lateral forces. The expressions developed herein are a means of quantifying the effect of unidirectional or bidirectional shear forces on the seismic behavior of these members in a simplified 
manner and at the macro-structural level. This information enables the designer to make decisions about the level of performance in analyses for the design and/or assessment of the seismic behavior of columns that are likely to be subjected to bidirectional loads.

However, in the ultimate limit state, phenomena that have not been considered in this study may interact with those considered here. Among these effects, shape effects, reinforcement details (such as lap splices, bonds and anchorage mechanisms), rebar buckling, strain rate effects and interactions with torsion, can be highlighted. Further research is needed to identify the possible interactions among these different effects.

The most relevant conclusions that can be drawn from the present study are given below.

1) Shear forces consume part of the strength capacity of stirrups that is required for concrete core confinement. Hence, the ductility and strength of the core concrete is reduced. A practical formulation was developed in this paper to account for this reduction.

2) In the developed model, the total lateral strain is considered to accumulate shear-related strains and confinement strains additively. This hypothesis has been shown to be plausible and to produce good results.

3) Under bidirectional lateral loads, a strain demand on the stirrups is produced by shear forces that acts concurrently with the bending and axial forces. This shear-produced strain in a transverse reinforcement decreases the deformation capacity required to confine the concrete core when the lateral load acts in an orthogonal direction. Consequently, the ultimate strain in the confined concrete is diminished. Methods for estimating this strain have been presented in this paper.

4) The decrement in the deformation capacity of both the confined concrete and the concrete cover from previously applied lateral strains can be obtained using the dilatancy modulus.

5) The effect of the tension shift is a function of the shear demand, the axial load and the mechanical capacity of the transverse reinforcement provided: however, a fixed relationship was not found in this study. A practical formulation based on the mechanism of compression strut was developed to account for tension shift effects on the moment-curvature relationship and the plastic hinge length.

6) The recommendations and formulations developed in this study were used in conjunction with a concentrated plasticity model to obtain the capacity curve of the column under both unidirectional and bidirectional lateral loads. The analytical results were compared to the experimental measurements of force and displacement with very good agreement.

\section{Acknowledgements}

The present research study is part of an investigation being carried in the framework of the projects entitled "Seismic assessment of reinforced concrete structures" (BIA2006-05614) and “Assessment of deteriorated, repaired and strengthened structures” (BIA2009-11764), co-financed by the Spanish Ministry of Science and Innovation and the European Funds for Regional Development (FEDER). The authors would like to thank the companies CELSA Barcelona and Prefabricats Pujol S.A. for their contributions to the experimental program, and the members of the Structural Technology Laboratory of UPC and the following persons for technical support: Mrs. Mireia Pujol, Mr. José Rico and Mr. Javier Muñoz.

\section{References}

[1] CEB, Telford T. RC Frames under Earthquake Loading: State of the Art Report. London: Comité eurointernational du béton; 1996.

[2] Qiu F, Li W, Pan P, Qian J. Experimental tests on reinforced concrete columns under biaxial quasi-static loading. Eng Struct 2002;24:419-28. doi:10.1016/S0141-0296(01)00108-0.

[3] Kawashima K, Watanabe G, Hayakawa R. Seismic Performance of RC Bridge Columns subjected to Bilateral Excitation. Proc. 35th Jt. Meet. Panel Wind Seism. Eff. UJNR, , vol. 35, Tsukuba Science City: Public Works Research Institute; 2003, p. 193-207.

[4] TSUNO K, PARK R. Experimental Study of Reinforced Concrete Bridge Piers Subjected To BiDirectional Quasi-Static Loading. Struct Eng / Earthq Eng 2004;21:11S-26S. doi:10.2208/jsceseee.21.11s.

[5] Rodrigues H, Arêde A, Varum H, Costa AG. Experimental evaluation of rectangular reinforced concrete column behaviour under biaxial cyclic loading. Earthq Eng Struct Dyn 2013;42:239-259. doi:10.1002/eqe.2205. 
[6] Wong YL, Paulay T, Priestley MJN. Response of circular reinforced concrete columns to multi-directional seismic attack. ACI Struct J 1993;90:180-91.

[7] Priestley MJN, Verma R, Xiao Y. Seismic Shear Strength of Reinforced Concrete Columns. J Struct Eng 1994;120:2310-29. doi:10.1061/(ASCE)0733-9445(1994)120:8(2310).

[8] Kowalsky MJ, Priestley MJN. Improved Analytical Model for Shear Strength of Circular Reinforced Concrete Columns in Seismic Regions. ACI Struct J 2000;97:388-96.

[9] Osorio E. Effects of cyclic biaxial shear loading on the seismic response of RC columns (In Spanish). Universitat Politècnica de Catalunya, 2012.

[10] Park R, Paulay T. Reinforced concrete structures. New York: Wiley; 1975.

[11] Mander JB, Priestley MJN, Park R. Theoretical Stress-Strain Model for Confined Concrete. J Struct Eng 1988;114:1804-26. doi:10.1061/(ASCE)0733-9445(1988)114:8(1804).

[12] Razvi S, Saatcioglu M. Confinement Model for High-Strength Concrete. J Struct Eng 1999;125:281-9. doi:10.1061/(ASCE)0733-9445(1999)125:3(281).

[13] Baker ALL, Amarakone AMN. Inelastic hyperstatic frames analysis. Spec Publ 1965;12:85-142.

[14] Corley WG. Rotational capacity of reinforced concrete beams. Skokie, Ill.: Portland Cement Association, Research and Development Laboratories; 1966.

[15] Scott M, Fenves G. Plastic Hinge Integration Methods for Force-Based Beam-Column Elements. J Struct Eng 2006;132:244-52. doi:10.1061/(ASCE)0733-9445(2006)132:2(244).

[16] Paulay T, Priestley JN. Seismic Design of Reinforced Concrete and Masonry Buildings. Wiley; 1992.

[17] Vecchio FJ, Collins MP. The Modified Compression-Field Theory for Reinforced Concrete Elements Subjected to Shear. ACI Struct J 1986;83:219-31.

[18] Hsu TTC. Constitutive Laws of Softened Concrete in Biaxial Tension Compression. ACI Struct J 1995;92:562-73.

[19] Osorio E, Bairán JM, Marí AR. Lateral behavior of concrete under uniaxial compressive cyclic loading. Mater Struct 2012:1-16. doi:10.1617/s11527-012-9928-9.

[20] Vecchio FJ, Collins MP. Predicting the Response of Reinforced Concrete Beams Subjected to Shear using the Modified Compression Field Theory. ACI Struct J 1988;85:258-68.

[21] Bairan JM, Mari AR. Multiaxial-coupled analysis of RC cross-sections subjected to combined forces. Eng Struct 2007;29:1722-38. doi:10.1016/j.engstruct.2006.09.007.

[22] Ceresa P, Petrini L, Pinho R. Flexure-Shear Fiber Beam-Column Elements for Modeling Frame Structures Under Seismic Loading _ State of the Art. J Earthq Eng 2007;11:46-88. doi:10.1080/13632460701280237.

[23] Mohr S, Bairán JM, Marí AR. A frame element model for the analysis of reinforced concrete structures under shear and bending. Eng Struct 2010;32:3936-54. doi:10.1016/j.engstruct.2010.09.005.

[24] EHE. Code on Structural Concrete. EHE-08. Articles and Annexes 2008;Act 1247/2.

[25] ACI. ACI 318-11 Building code requirements for structural concrete and commentary 2011.

[26] Turmo J, Ramos G, Aparicio AC. Shear truss analogy for concrete members of solid and hollow circular cross section. Eng Struct 2009;31:455-65. doi:10.1016/j.engstruct.2008.09.002.

[27] CALTRANS. Caltrans seismic design criteria, version 1.72013.

[28] Eurocode 8. Design provisions for earthquake resistance of structures : Part 2 Bridges 2012;UNE-EN 199.

[29] Priestley MJN, Park R. Strength and Ductility of Concrete Bridge Columns under Seismic Loading. ACI Struc J 1987;84:61-7. doi:10.14359/2800.

\section{Notation}

$A_{s t}$ is the area of the stirrups or the spiral

$D_{c}$ is the center-to-center diameter of the stirrups

$E_{c}$ is the concrete modulus of elasticity

$E_{s}$ is the elastic modulus of the longitudinal reinforcing steel 
$E_{s t}$ is the elastic modulus of the transverse reinforcement

$\mathrm{f}_{\mathrm{c}}$ is the unconfined concrete compression strength

$f_{c c}$ is the peak strength of the confined concrete

$f_{y}$ is the yielding strength of the longitudinal reinforcing steel

$f_{y t}$ is the yielding strength of the stirrups

$L$ is the shear span

$L_{e}$ is the column length plus the length corresponding to the strain penetration

$L_{p}$ is the equivalent plastic hinge length

$M_{f}$ is the ultimate bending moment capacity

$M_{f v}$ is the effective flexural strength

$M_{y}$ is the yielding moment

$M_{u}$ is the ultimate moment

$P$ is the axial load

$s$ is the stirrups spacing

$V_{d}$ is the shear force demand

$\mathrm{V}_{\mathrm{s}}$ is the transverse reinforcement contribution to shear strength

$V_{s}^{\theta=45^{\circ}}$ is the shear force strength provided by the stirrups for a crack inclination angle of $45^{\circ}$

$V_{p}$ is the arch effect contribution to shear force strength

$\mathrm{V}_{u}$ is ultimate shear force strength

$x$ is the distance required to develop

$z$ is the lever arm

$\alpha$ is a factor that represents the confinement efficiency

$\alpha_{b}$ is the coefficient of the strain penetration

$\Delta_{f}$ is the flexural displacement

$\Delta_{p}$ is the plastic displacement

$\Delta_{S}$ is the displacement from the shear

$\Delta_{y}$ is the elastic displacement

$\Delta_{\theta}$ is the displacement from strain penetration of the longitudinal rebar

$\Delta M_{v}$ is the increment in the internal bending moment at the section that is produced by the shear force

$\Delta T$ is the increment in the tensile force at the longitudinal reinforcement from shear

$\varepsilon_{c p}$ is the ultimate strain in the unconfined concrete

$\varepsilon_{c u, e}^{i}$ is the effective deformation capacity of the concrete

$\varepsilon_{s v}^{j}$ is the strains induced by the shear forces in $j=y$ or $x$ direction

$\varepsilon_{S C}^{i}$ is the strains produced by the dilatancy of concrete in compression in $i=x$ or $y$ direction

$\varepsilon_{s t}^{i}$ is the total strain at the stirrup in $i=x$ or $y$ direction

$\varepsilon_{s u}^{i}$ is the ultimate strain in the transverse steel reinforcement in $i=x$ or $y$ direction

$\theta_{p}$ is the angle of the compression strut with respect to the column longitudinal axis

$\rho_{s}$ is the volumetric ratio of the transverse reinforcement

$\phi_{y}$ is the yielding curvature

$\phi_{p}$ is the plastic portion of the curvature

$\sigma_{e, x}$ is the confinement stress in the $\mathrm{X}$ direction 
$\sigma_{e, y}$ is the confinement stress in the $\mathrm{Y}$ direction

$\sigma_{s v}$ is the stress in the transverse reinforcement from the shear force

$\sum \frac{A_{s t}}{s}$ is the area of the transversal reinforcement per unit length

$\psi_{u}$ is the ultimate dilation ratio 